\title{
Recent changes in continentality and aridity conditions over the Middle East and North Africa (MENA) region and their association with circulation patterns
}

\author{
Ahmed M. El Kenawy ${ }^{1,2 *}$, Matthew F. McCabe ${ }^{1}$, Sergio M. Vicente-Serrano ${ }^{3}$, Sayed \\ M. Robaa ${ }^{4}$, Juan I. Lopez-Moreno ${ }^{3}$ \\ 1. Water Desalination and Reuse Center, Division of Biological and Environmental Sciences and Engineering, King Abdullah \\ University of Science and Technology, Saudi Arabia. \\ 2. Department of Geography, Mansoura University, Mansoura, Egypt. \\ 3. Instituto Pirenaico de Ecología, Spanish National Research Council (IPE-CSIC), Zaragoza, 50059, Spain. \\ 4. Department of Astronomy, Space Science and Meteorology, Faculty of Science, Cairo University, Egypt. \\ *Corresponding author: (kenawy@mans.edu.eg)
}

ABSTRACT: A long-term (1960-2013) assessment of the variability of continentality and aridity conditions over the Middle East and North Africa (MENA) region was undertaken. Monthly gridded temperature and precipitation data from the Climate Research Unit (CRU) (TS3.22 version) were used to compute the Johansson Continentality Index (JCI) and the Marsz Oceanity Index (MOI). In addition, the De Martonne index and the Pinna index were employed to assess recent changes in aridity conditions. All indices revealed a statistically significant increase in the continental influences over the region, particularly in the Nile Basin and the Fertile Crescent. For aridity, the results suggested a generally statistically insignificant increase, with the most rapid changes occurring over the most humid regions (i.e., the Ethiopian Highlands and the Fertile Crescent). In order to explain the observed changes in the continentality and aridity conditions, we assessed the relationship between aridity and continentality indices and a wide range of large-scale circulation patterns. Results indicate that the spatial variability of continentality (as well as aridity) was closely coupled with the Atlantic modes of variability, e.g., the Eastern Atlantic pattern and the Atlantic Meridional Mode, compared to those of the Mediterranean Sea and the Indian Ocean. The results of this work highlight change processes in two important climate features in one of the hottest regions on Earth. Improving our understanding of the spatio-temporal characteristics of climate continentality and aridity has implications for a diversity of socio-political, economic, hydrological and ecological activities in the MENA region. 
KEY WORDS: Continentality, Aridity, Precipitation, Temperature, Circulation Patterns, MENA.

Running title: Continentality and aridity in the MENA region.

\section{INTRODUCTION}

The global climate has warmed over the past few decades, as a consequence of both natural processes and anthropogenic factors (Trenberth, 2011, Bindoff et al., 2013). Previous studies have referred to the Mediterranean and the Middle East region as a "hot spot" in terms of climate change, with more rapid increases in surface temperature relative to the global mean (e.g., Nasrallah and Balling, 1993, Giorgi, 2006, Tanarhte et al., 2012). For example, Nasrallah and Balling (1993) reported an increase in temperature records over the Middle East during the period $1945-1990$ at an average rate of $0.07^{\circ} \mathrm{C} /$ decade, which is higher than the corresponding linear trends for global land areas $\left(0.05^{\circ} \mathrm{C} /\right.$ decade $)$. Using a range of gridded data sets, Tanarhte et al. (2012) found a generally upward trend of temperature and a downward tendency in precipitation over vast areas of the Middle East. The largest changes in temperature mostly occurred in the Mediterranean countries (Morocco, northern Algeria and Tunisia) and the Arabian Gulf, while the least warming was evident over northern Iraq, Jordan and Iran. Numerous studies confirm the temperature rise at a sub-regional scale over the Middle East and North Africa (MENA) region (e.g., Hassanean and Abdel Basset, 2006, El Kenawy et al., 2009, Kafle and Bruins, 2011, Almazroui et al., 2012).

The recent observed changes in climate variables (e.g., temperature and precipitation) raise the question of how continentality and aridity might respond to climatic changes over the MENA region: a region that is subjected to different types, frequencies, and magnitudes of climate and weather events (Donat et al., 2014). Aridity (the opposite of humidity) refers to the degree to which a climate lacks effective and life promoting moisture over a region (Maliva and Missimer, 2012), while continentality provides an indication of the degree to which a point on the Earth's surface is subject to the influence of a landmass (Glickman, 2000). Given the roles of temperature and precipitation in describing the characteristics of continentality and aridity, variability of these indicators over space and time can be seen as an indicator of changes in 
67 various climate variables (e.g., cloudiness, pressure and humidity). In addition, in areas of

68 limited water resources and high population growth like the MENA region, recent climate warming may increase the frequency and severity of climate extremes related to continentality and aridity. Bannayana et al. (2010) have addressed the effect of aridity on rainfed crop yields in northeastern Iran, suggesting an inverse and strong correlation between aridity and crop yield. In the same context, continentality and aridity conditions can exert significant influences on fauna and flora through certain physiological thresholds of temperatures and water availability (Pal and Eltahir, 2016). From a socio-political perspective, Burke et al. (2009) found that regions suffering from rapid climate changes are more likely to experience civil wars and political instability.

While previous studies of climatic variability in the MENA region have focused mainly on an analysis of air temperature (e.g., El Kenawy et al., 2009, Almazroui et al., 2012) and precipitation (e.g., Nazemosadat and Cordery, 2000, Raziei et al. 2012, El Kenawy et al., 2014, Deng et al., 2015), more attention to other related meteorological indicators, such as changes in continentality and/or aridity were conducted over Europe (e.g., Brázdil et al., 2009, Croitoru et al., 2013), China (e.g., Qian and Zhou, 2014) and the northern Mediterranean (e.g., Baltas, 2007, Deniz et al., 2011, Andrade and Corte-Real, 2014). A representative example is Baltas (2007) who described the continental and arid conditions in northern Greece during the period 1965-1995 and identified a superior performance of particular indices (e.g., Johansson and De Martonne indices) compared to other indices (e.g., Kerner and Pinna indices). Likewise, Brázdil et al. (2009) analyzed changes in continentality over the Czech Republic during the period 1961-2005, suggesting an increase from the late 1960s.

In the MENA region, where climate characteristics are strongly influenced by the proximity of oceans and seas (e.g., the Atlantic Ocean, the Indian Ocean, the Mediterranean Sea, the Red Sea and the Arabian Gulf) as well as large extensions of land masses across Asia and Africa, characterization of continentality and aridity regimes is largely lacking. This is primarily due to the lack of a network of observatories with long, homogeneous and spatially dense climatic records, which makes the region poorly represented in global perspectives of climate changes. A 
limited number of studies have examined continentality and aridity changes over the region, albeit with a particular focus on Iran (e.g., Shifteh et al., 2013, Tabari and Aghajanloo, 2013, Tabari et al., 2014). One example is Tabari et al. (2014), who analyzed the spatial and temporal variations of the De Martonne and Pinna aridity indices over Iran based on observational temperature and precipitation data for a 40-year period (1966-2005).

Recalling that the spatial and temporal variability of climate has been described as being driven by the atmospheric-oceanic circulation in many areas across the MENA region (see, for example, Nazemosadat and Cordery, 2000, Rahimzadeh et al., 2009, Raziei et al., 2013, El Kenawy et al., 2010, 2014), it is interesting to explore the dependency between continentality and aridity conditions and circulation patterns. While the climate of the MENA region is transitional, with both mid-latitude and sub-tropical configurations influencing the region, the associations between continentality and aridity changes and teleconnections have not yet been comprehensively approached, either at the level of the whole region or at a sub-regional scale. Investigating the association between climate aridity and continentality and the variability of circulation patterns is not only informative when examining climate model simulations, but also in advancing our current understanding of the implications of changes in these climatic indicators for both humans and natural systems across the region (e.g., water resources agriculture, human health,....etc.) (Vicente-Serrano et al., 2015).

The main aims of the present study are (1) to investigate recent spatial and temporal changes in the continentality and aridity characteristics over the MENA region during the period 1960-2013 by using a set of indices, and (2) to analyze the possible large-scale circulation configurations, summarized by a range of teleconnection indices, behind the observed regional variability of continentality and aridity. Overall, this research provides the first comprehensive attempt to characterize long-term (1960-2013) changes in continentality and aridity conditions in the MENA region, allowing for the definition of its different sub-regional response to recent climate warming.

\section{STUDY AREA}


The MENA region extends over 24 countries in Africa and Asia, representing approximately $10 \%$ of the world's total land area (approximately $14.5 \times 10^{6} \mathrm{~km}^{2}$ ) and ranging from the latitudes of $1^{\circ} 39^{\prime} \mathrm{S}$ and $39^{\circ} 48^{\prime} \mathrm{N}$ and longitudes from $17^{\circ} 06^{\prime} \mathrm{W}$ to $63^{\circ} 20^{\prime} \mathrm{E}$ (Fig. 1). In addition to the large landmass, the region incorporates a variety of topographic conditions, with a relatively low and uniform flat terrain, surrounded by a range of mountains (e.g., Atlas, Zagros, Alborz, Assir and the Ethiopian Highlands).

Due to its geographical location, wide altitudinal range and topographical features, the climate of the MENA region is transitional, with a considerable influence of both mid-latitude and subtropical configurations. As illustrated in Fig. 2, the study domain presents considerable regional variations in terms of climatic regimes. Generally, total annual rainfall can vary between $65 \mathrm{~mm}$ in the Sahara and 770mm in the Ethiopian Highlands. Peak rainfall over the Ethiopian highlands and the Nile Basin occurs in late summer and early autumn, while rainfall for the majority of other regions mostly occurs during winter and early spring. Overall, the rainiest areas are located in the main mountain sectors due to orographic precipitation (e.g., the Ethiopian Highlands). In accordance with rainfall variability, temperature is also characterized by markedly high intraannual variability, with the annual mean temperature ranging from $17.3^{\circ} \mathrm{C}$ in Iran to $26.9^{\circ} \mathrm{C}$ in the African Horn, depending on latitude and elevation.

\section{DATA AND METHODS}

\subsection{Climate data}

In the MENA region, observational data are sparse in both space and time: a result of both the cost of equipment installation, maintenance and archiving, combined with historical instability and the continuity of meteorological agencies (El Kenawy and McCabe, 2015). With the availability of good quality gridded climate data, it is possible to characterize continentality and aridity conditions in the region without solely relying on in-situ networks. In this analysis, we employed two gridded monthly temperature and precipitation gauge-based data sets, compiled by the Climate Research Unit (CRU) at the University of East Anglia (UK) (http://www.cru.uea.ac.uk/cru/data/hrg/cru_ts_3.22/). CRU (v.3.22) is a global product produced at a $0.5^{\circ}$ grid resolution for the period 1901-2013 (Harris et al., 2014). The relatively high spatial resolution ensures a robust representation of regional behavior and variability of climatic 
conditions. CRU (v.3.22) has been assessed for potential data inhomogeneities and detection and elimination of anomalous data (Harris et al., 2014). In our domain, CRU (v3.22) has previously been validated against in situ data in some provinces and is considered as a representative and reliable source of data (e.g., Almazroui et al., 2012, Tanarhte et al., 2012, El Kenawy and McCabe, 2015). Here, we used the monthly total precipitation (mm) and mean temperature $\left({ }^{\circ} \mathrm{C}\right)$ data sets for the grid points over the MENA region $(N=5718)$. Given that climatic data from meteorological land stations are unevenly distributed over space and time in the earlier decades of the 20th century, we restricted our analysis to the period from 1960 to 2013. Bhowmik and Costa (2015) discuss the impacts of the number and representativeness of climate data on accuracy and precision in their spatial interpolation.

\subsection{Continentality and aridity indices}

Since the release of the Köppen and Geiger climate classification in 1928, climatic indices have frequently been used as diagnostic tools to characterize and classify climate conditions (e.g., Baltas, 2007, Deniz et al., 2011, Qian and Zhou, 2014). Most continentality and aridity indices are based on meteorological or hydrological variables. Recalling that the distribution of temperature over the Earth is highly dependent on variations in radiation and heat, which are largely controlled by the distribution of incoming solar radiation, continentality indices explicitly rely on temperature data. A comprehensive review of continentality indices is given in Minetti (1989). Aridity has commonly been defined using a range of indicators to better reflect the potential impacts of climate change on different disciplines (e.g., water resources, agriculture, crop yield etc.). While some indices rely mainly on temperature and precipitation data, such as the De Martonne and Pinna indices (Zambakas 1992), other indices included more complex methods of aridity estimation (e.g., dryness index and the UNEP index [1997]) for an accurate quantification of the atmospheric evaporative demand. However, these latter methods require a much greater amount of climatic data (e.g., wind speed and relative humidity), which are not routinely available in many regions worldwide, but especially in the MENA region.

\subsubsection{Continentality indices}

Here, we employ the Johansson Continentality Index (JCI) and the Marsz Oceanity Index (MOI) to characterize continentality conditions. While other indices (e.g., the diurnal temperature 
190

191

192

193

194

195

196

197

198

199

200

201

202

203

204

205

206

207

208

209

210

211

212

213

214

215

216

217

218

219

range) could provide an informative indicator of continentality variations, the access to daily observed climate records is not possible over vast areas of the MENA region. Recalling that continental climates are typically associated with larger intra-annual temperature ranges compared with maritime climates, continentality indices are generally formulated as a function of two physically-related components: the amplitude of temperatures of the warmest and the coldest month and the geographical latitude (Deniz et al., 2011). The values of each of the investigated indices were computed on a yearly basis over each grid box in the region for the period 1960-2013.

Following Gavilan (2005) and Baltas (2007), the continentality indices were formulated as:

$J C I=\frac{1.7 \Delta T}{\sin (\varphi)}-20.4$

$M O I=\frac{0.731 \varphi+1.767}{\Delta T}$

where $\Delta T$ is the annual range of monthly mean air temperatures $\left({ }^{\circ} \mathrm{C}\right)$, and $\varphi$ is the geographic latitude (degrees) of each grid box. The climate types corresponding to the index values of JCI and MOI are summarized in Table 1.

\subsubsection{Aridity indices}

In this study, the definition and characterization of aridity were undertaken using two widely used indices: the De Martonne aridity index and the Pinna index. These indices provide a direct measure of the temperature and precipitation forcing in the study domain. Recalling that the definition of the wet season varies among the different sub-regions over the MENA region (see Fig. 2), we calculated the aridity indices on an annual rather than seasonal time scale. This primarily impacts the De Martonne index, given that the Pinna index cannot be calculated for shorter than annual time scales.

\section{- De Martonne aridity index}

The De Martonne index is among the more widely used aridity indices in the literature, due to its efficiency and relevance with respect to identification of dry/humid conditions in different climate zones worldwide (e.g., Baltas 2007, Shahid, 2010, Zarghami et al. 2011). The index was calculated, as: 
De Martonne $=\frac{P}{\mathrm{~T}+10}$

where $\mathrm{P}$ is the annual total amount of precipitation $(\mathrm{mm})$ and $\mathrm{T}$ is the mean annual air temperature $\left({ }^{\circ} \mathrm{C}\right)$.

\section{- Pinna index}

The Pinna index is another common approach that determines aridity conditions based on temperature and precipitation data (Deniz et al. 2011). In addition to the annual mean temperature and precipitation, this index also accounts for air temperature and precipitation of the driest month in the year, as follows:

Pinna $=\frac{1}{2}\left(\frac{P}{T+10}+\frac{12 P_{d}^{\prime}}{T_{d}^{\prime}+10}\right)$

where $\mathrm{P}$ and $\mathrm{T}$ are the multi-annual mean values of precipitation and air temperature, respectively, and $P_{d}^{\prime}$ and $T_{d}^{\prime}$ are the mean values of precipitation and air temperature of the driest month, respectively. The classification of aridity degrees, according to the Pinna index, is shown in Table 1. As noted, a region is characterized as dry when the values of the index are lower than 10, as semi-dry when they range between 10 and 20, and denotes as humid when above 20 .

\subsection{Temporal evolution of continentality and aridity indices}

In this study, we used the ordinary least squares (OLS) regression method to detect temporal trends in the investigated continentality and aridity indices. The aim was to investigate continentality and aridity trends in a region that has a large latitudinal range, with different climate regimes. The OLS procedure allows for defining whether the detected changes were a consequence of a long-term trend or just an oscillation. The significance of the trend was assessed using the Mann-Kendall tau test at the $95 \%$ significance level (p-value $<0.05$ ). The Mann-Kendall statistic is a rank-based non-parametric test, which is robust to outliers and does not assume any underlying probability distribution of the data series (Zhang et al., 2001).

\subsection{Links of continentality and aridity indices with circulation patterns}

In order to explore the extent to which circulation patterns determines spatial patterns of continentality and aridity over the MENA region, we employed a set of 19 atmospheric-oceanic circulation patterns, based on data obtained from the NOAA/NCEP Climate Prediction Centre 
250 (http://www.cpc.noaa.gov/data/teledoc/telecontents.shtml) and the Climate Research Unit of the 251 University of East Anglia (http://www.cru.uea.ac.uk/cru/data/pci.htm). A list of these circulation 252 patterns and their definitions is provided in Table 2. Further details on the calculation and 253 geographical domain of the investigated circulation patterns can be found via 254 http://www.cpc.noaa.gov/data/teledoc/telecontents.shtml. While the climate of the western parts of the MENA region is influenced by the Atlantic Ocean and the position of the Icelandic low and Azores high pressure regions, the eastern region is mainly influenced by the maritime tropical air masses (monsoon type), polar fronts and central Asian air masses (Raziei et al., 2013, Almazroui et al., 2015). For this reason, we believe that the chosen patterns are likely important in explaining the climatology of continentality and aridity across the MENA region, as they represent the dominant modes of multi-annual variability in the atmosphere that summarize the Atlantic, Indian, Mediterranean and Middle East systems, as reported in previous works (e.g., Vicente-Serrano et al., 2009, Raziei et al., 2013, Berhane et al., 2014).

Here, we associated the annual time series of the continentality and aridity indices with those of the aforementioned circulation patterns for the period 1960-2013 using the Pearson correlation coefficient. Although the strength and spatial distribution of the dependency between continentality and aridity and circulation modes can differ from one month to the other (as patterns of climate can respond differently to atmospheric-oceanic processes depending on time and space scales), we believe that assessing this association at the annual time scale is informative in the sense that it identifies the phases of the circulation modes, which are responsible for the observed variability in the annual mean climatology of continentality and

272 aridity across the region. Prior to correlating continentality and aridity indices with the 273 circulation patterns for each grid box, the time series of the continentality and aridity indices 274 were detrended to remove possible impacts of trends introduced in the time series and also to 275 separate the observed pattern of variability from any global warming signal that may be present 276 in the data.

278 In order to establish which circulation patterns are most associated with the spatial distribution of 279 continentality and aridity in the MENA region, a T-mode of the Principal Component Analysis 280 (PCA) was applied (Wilks et al., 2011). The PCA is a multivariate variable-reduction procedure, 
which is commonly used in climate research for defining the leading spatial patterns of climate variability (Wilks, 2011). In this work, the calculated Pearson correlation coefficients between circulation patterns and continentality-aridity indices were used as inputs in the PCA. To facilitate the spatial reasoning of the PCs, we only retained those PCs with eigenvalues greater or equal to 1 . Then, the maximum variance (Varimax) method was applied to the unrotated PCs to redistribute the final explained variance, and to obtain more stable and physically robust patterns. According to Wilks (2011), the Varimax rotation method assumes that each defined factor has a small number of large loadings (correlations), providing a clearer division between the retained components. To summarize the PCA results, we compared the eigenvalues of the different PCA axes corresponding to each continentality or aridity index and the axis loadings of circulation patterns. In addition, the computed PC scores were mapped for each retained component, giving insights into the possible spatial differences in the influence of the circulation patterns on the spatial variability of continentality and aridity.

\section{RESULTS AND DISCUSSION}

\subsection{Spatial distribution of the indices}

Fig.3 illustrates the spatial distribution of the continentality and aridity indices, calculated for the period 1960-2013. The results reveal a high degree of consistency among the continentality indices, with a general gradient from south to north. The spatial structure of MOI values overlaps with that of JCI, albeit with a reversed sign (i.e., lower MOI values correspond to more continental climate and vice versa). According to the JCI classification, maritime characteristics $(\mathrm{JCI}<33)$ dominated in coastal areas along the Atlantic Ocean, the Mediterranean Sea, the Red Sea and the Arabian Sea. The only exception was in areas adjacent to the Arabian Gulf, where maritime influences became less important (JCI>66). Over the Arabian Gulf area, the continental influence of Central Asia on the regional climate is more pronounced than the influence of the Arabian Gulf itself. This feature is confirmed in Fig. 4, where the Pearson coefficient between JCI values and distance to water bodies is 0.22 over Iran, compared to 0.85 for Morocco, 0.79 for the Sahara and 0.51 for the Fertile Crescent. Figures 3 and 4 also suggest that the maritime characteristics were associated with altitude in some regions. For example, the correlation between altitude and MOI reached 0.47 over the western foothills of the Ethiopian Highlands. This pattern can be attributed to the direction of the mountain ranges, which interrupts the 
eastern movement of weather systems, dividing the region into a western windward area with high maritime influences, and an eastern leeward area with lower marine impacts and higher temperatures associated with adiabatic sinking. Numerous studies have highlighted the important role of westerly winds in climate variability over the Blue Nile and the Ethiopian highlands (e.g., Levin et al., 2009, Diro et al., 2011, Bwehane et al., 2014). In contrast, the hyper-continental climate is specific to the southern parts of the African Horn, with JCI values generally above 90. This high magnitude of JCI can be explained by the location of this area in the equatorial region, where the annual range of temperature is markedly low.

Fig. 3 illustrates the spatial distribution of the De Martonne and Pinna aridity indices. The results reveal a high spatial agreement between the two indices (Pearson’s $r>0.98$ in all sub-regions), with the arid climate dominating the majority of the study region. As expected, the inner regions (particularly in the Sahara and the Arabian Peninsula) were the driest, with Pinna and De Martonne values below 2 and 5, respectively. In contrast, the western parts of the Ethiopian Highlands and South Sudan were the wettest. This pattern can be seen in the context of the high annual rainfall associated with the orographic influence of the Ethiopian Highlands (see Fig. 2). The aridity values of both De Martonne and Pinna indices correlated positively with altitude in all sub-regions, with the highest association found in the Ethiopian Highlands and the Arabian Peninsula, while the lowest correlation $(r<0.1)$ occurred over the African Horn and Sahara (Fig. 4). In contrast, the aridity values correlated negatively with distance to water bodies in the Sahara, the Arabian Peninsula and Morocco, while they correlated positively over the Ethiopian Highlands and the Nile Basin.

In Fig. 5, we compare the relative areal proportion represented by each climate class. The results indicate some differences between the indices in terms of their ability to classify the continentalmaritime conditions over the region. According to JCI, the whole region was mainly continental (83.1\% of the total area), compared to $11.9 \%$ for maritime climate and 5\% for hyper-continental climate. Spatially, a continental climate mainly characterized the Fertile Crescent (97.2\%), Iran (96.8\%), the Arabian Peninsula (86.7\%) and the Nile Basin (85.1\%). The continental climates under MOI classification were markedly over-represented compared to those of JCI classification, while maritime climates were under-represented. For aridity, both indices revealed 
that the MENA region was almost entirely characterized by arid and semi-arid climates (Fig. 5). Nonetheless, the arid area represented by the Pinna index was considerably higher than that identified by the De Martonne: a finding reinforced by Tabari et al. (2014) over Iran. In terms of climate variations, almost the entire range of the Pinna classification categories was identified in the Ethiopian Highlands as well as the Nile Basin region, albeit with the humid climate represented by a small area (wetlands of the Sudd) over the Nile Basin (0.8\%) (Fig.5). Our results concur with the findings of the few studies assessing aridity characteristics in specific areas over the MENA region. For example, our results demonstrate that the arid and semi-arid climates covered approximately 92\% of Iran according to the De Martonne index. Using the same index and observational data, Tabari et al. (2014) found that about $88 \%$ of the country was classified as dry and semi-dry. These slight variations can be associated with specific features of the CRU data sets, which can differ from observational data as a function of the number of available observatories over space and time and/or the selection of the interpolation algorithm. Given that the spatial distribution of De Martonne values presents a similar behavior to that of the Pinna Index, it may be suggested that the De Martonne Index is more applicable for aridityhumidity classification over the MENA region, as it provides more climate categories ranging from dry to very humid. Similar results were found by Croitoru et al. (2013) in Romania, Baltas (2007) in Greece, Deniz et al. (2011) in Turkey and Tabari et al. (2014) in Iran.

\subsection{Spatial and temporal evolution of continentality and aridity indices}

A summary of changes in the investigated indices over the period 1960-2013 is provided in Table 3, with their spatial distribution illustrated in Fig. 6. Trend detection of the JCI series suggests an increase in the continentality conditions in the MENA region and across all subregions. The amount of increase varies considerably over space, with the largest changes over the Nile Basin (1.09 unit per decade). In contrast, regions with the lowest and statistically insignificant increase were found in the western areas of Morocco, northwest Iran, the southern African Horn and southeast Arabian Peninsula (Fig. 6). MOI trends agree well with those of JCI, where the results generally suggest a decrease in the maritime influences in the MENA region over the 54-year period. In accordance with JCI, the Nile Basin showed the most rapid decrease in the maritime influences, compared to other regions (especially Morocco and Iran). The tendency towards a more continental climate in the MENA region can be explained by the 
374 upward trends in surface air temperature, which has been reported in a range of regional studies

375 (e.g., Hassanean and Abdel Basset, 2006, El Kenawy et al., 2009, Tabari et al., 2012). Table 3

376 confirms that the increase in summer Tmax was more significant than changes in winter Tmin

377 over the 54-year period, suggesting an increase in the annual temperature range and thus

378 increasing continentality over the region. For example, the increase in summer Tmax was

379 statistically significant $(\mathrm{p}<0.05)$ in all sub regions, with values ranging from $0.11^{\circ} \mathrm{C}$ per decade

380 (African Horn) to $0.40^{\circ} \mathrm{C}$ per decade (Nile Basin). Our finding of the recent upward trend in

381 continentality over the MENA region is interesting from a climatological point of view. This is

382 principally because Hirschi et al. (2007) and Brazdil et al. (2009) observed smaller changes in

383 continentality conditions across the mid-latitudes, compared to the high latitudes (e.g., Arctic and

384 Antarctica).

385

386

Table 3 suggests a general decrease in aridity index values (i.e., more aridity) from 1960 to 2013, albeit only being statistically significant in the Ethiopian Highlands and the Fertile Crescent. The weakest changes were found in the most arid regions (i.e., in the Sahara and the Arabian Peninsula), with a negligible linear trend. This pattern can be associated with changes in rainfall, which were generally insignificant over the MENA region (Donat et al., 2014). Overall, our results on the increasing tendency in aridity over the study domain fit well with the results of previous works (e.g., Kafle and Bruins, 2009, Bannayana et al., 2010, Tabari et al., 2014). For example, Tabari et al. (2014) found an increasing tendency in the aridity over Iran, but with considerable regional differences. Their results indicated a stronger increase in aridity conditions in the western and northwestern areas of the country, with relative changes on the order of $18 \%$ to $54 \%$. As the MENA region is largely classified as arid and semi-arid, there is a growing water scarcity due to high consumption for agricultural and domestic use, besides low water quality. Accordingly, the increase of aridity in the region, though being statistically insignificant in most areas, could have adverse impacts, particularly on water resources and agriculture sectors.

401 To characterize spatial changes in the continentality and aridity conditions in the region over the 402 54-year study period, we assessed shifts in the climate class by comparing the class of climate 403 aridity and continentality at each grid pixel in the first decade of the study period (1960-1969) 404 with that of the last decade (2004-2013). Fig. 7 indicates that the MENA region generally 
experienced a relative increase (\%) in continentality influences. In most cases the observed increase in continentality values does not necessarily imply a shift in the climate class. Shifts in climate class were more pronounced in regions with more varying climates (e.g., the Ethiopian Highlands, the Nile Basin, Morocco and Iran). In accordance with continentality indices, the shift in climate aridity classes was mostly found in the Ethiopian Highlands, the southern parts of the Nile Basin, northwestern Iran and the Mediterranean coasts of Algeria and Morocco, where the areas shifted primarily from semi-arid to arid and from the Mediterranean climate to semiarid climate. In contrast, only very small areas in southern portions of the Nile Basin and the Ethiopian Highlands experienced a shift towards more humid conditions.

Table 3 reveals that regions that experienced significant warming in continental conditions showed less changes in their aridity indices, and vice versa. This behavior can be seen in the context that the MENA region experienced significant warming in temperature (Hassanean and Abdel Basset, 2006, El Kenawy et al., 2009, 2010, Kafle and Bruins, 2011, Almazroui et al., 2012), while changes in rainfall were generally inhomogeneous, with no evidence on significant changes across vast areas of the region (Nazemosadat and Cordery, 2000, Donat et al., 2014). The only exception corresponded to the Fertile Crescent, where all indices suggested significant changes in continentality as well as in aridity conditions. Recently, Rahman et al. (2015) found a statistically significant decline in annual rainfall over Jordan, at an average rate of $12 \mathrm{~mm}$ per decade. Given that the Fertile Crescent incorporates some of the poorest areas in the world, in terms of water resources availability (e.g., Gaza strip and Jordan), the observed rapid changes in both continentality and aridity could imply profound ecological and environmental consequences affecting this region, especially those related to irrigation requirements, energy and water resources management.

\subsection{Links to circulation patterns}

We applied the T-mode PCA, with Varimax rotation, to an array of Pearson correlation coefficients computed between a set of 19 atmospheric-oceanic circulation patterns and the detrended annual time series of each investigated continentality and aridity index for the period 1960-2013. Following the results of the Scree plot and the Kaiser test, only five significant PCs were retained for each index, which explained $79.6 \%, 79.4 \%, 81.5 \%$ and $81.4 \%$ of the total 
variance of JCI, MOI, De Martonne and Pinna indices, respectively. For simplicity, we only focus on the first three PCs corresponding to each index.

Fig. 8 summarizes the loadings (correlations) of the first three rotated PCs for each continentality and aridity index. Overall, results highlight the key role of the Atlantic Ocean on the spatial variability of continentality over the MENA region. In contrast, the influence of the circulation patterns associated with the Mediterranean Sea, as well as the Indian Ocean, were generally less significant. As illustrated in Fig. 8, the first PCA axis represented circulation patterns originating over the Atlantic Ocean, where the Atlantic Meridional Mode (AMM) index, the Atlantic Multidecadal Oscillation (AMO) index, the Atlantic Tripole SST EOF (ATSST) pattern and the the North Tropical Atlantic (NTA) index were the most important patterns controlling the spatial distribution of continentality. For the second PCA axis, the Scandinavian (SCA) pattern, the Southern Oscillation (SO) index, the Bombay SLP anomaly (BOMBAY) pattern and the Eastern Atlantic-Western Russian (EAWR) pattern were significantly coupled with continentality. According to the third rotated PC, most of the circulation patterns showed different loadings for JCI and MOI. For example, while some circulation patterns (e.g., the Tropical Southern Atlantic [TSA] index) showed a better association with JCI continentality (loadings=-0.90), it had a weak dependency (loadings=-0.14) with MOI.

Fig. 8 also illustrates the loadings of the first three significant PCs for the aridity indices. The circulation patterns showed consistent loadings for De Martonne and Pinna indices along the three axes. In accordance with continentality indices, the circulation patterns associated with the Atlantic Ocean (i.e., AMM, AMO, ATSST, NTA, EASLP and TSA) exhibited the largest loadings (correlations) on the first axis. Along this PC, all correlations between aridity and these circulation patterns were positive. Segele et al. (2009) confirmed the association between summer rainfall in the African Horn and the enhanced westerly advections of water vapor from the Atlantic Ocean. Our findings show that the loadings of the NAO, which is the dominant circulation pattern over the North Atlantic region, were negligible for both De Martonne and Pinna indices, suggesting a weak influence of the NAO on aridity variations in the MENA region. This finding supports Bannayana et al. (2010) who found that the correlation coefficient between aridity indices and the NAO did not exceed 0.18 across the Iranian territory. 
Nonetheless, it is worth noting that the association between aridity and changes in the circulation patterns could be seasonally dependent. This feature is particularly important for the NAO, as the links between the NAO and climate are best expressed during wintertime, relative to other periods of the year (Vicente-Serrano et al., 2009, Lopez-Moreno et al., 2011). We tested this hypothesis by assessing the association between seasonal and annual time series of circulation patterns (Table 4). As indicated, the results showed very high agreement between the seasonal and annual variability of the majority of the Atlantic circulation modes (e.g., AMM, AMO, ATSST and NTA), with Pearson coefficients generally above 0.80. As the continentality and Pinna indices can only be calculated at the annual scale, this high agreement suggests that the results obtained for the dependency between continentality and aridity indices and the circulation at the annual scale are not expected to vary significantly on the seasonal scale. For the NAO, the intra-annual variability was much higher, with Pearson coefficients ranging between 0.48 (winter) and 0.61 (spring). The second PCA correlated positively and strongly with the Mediterranean Oscillation (MO), the Southern Oscillation (SO), and the Sahel Rainfall (SR) Index, while it negatively correlated with the Bombay SLP anomaly (BOMBAY) and El Niño 1+2. Along this axis, the highest loadings were found for El Niño $1+2$, with -0.80 and -0.81 for De Martonne and Pinna indices, respectively. These high negative loadings suggest that the positive phase of El Niño 1+2 plays a significant role in enhancing aridity over some areas in the MENA region. Nazemosadat and Cordery (2000) found a significant association between rainfall and El Niño Southern Oscillation (ENSO) over Iran for the period 1951-1990. The variance of aridity in the third PC clearly suggests two particular circulation patterns impacting aridity variability over the MENA region: the Scandinavian (SCA) pattern, with loadings of -0.79 for both De Martonne and Pinna indices, and the East Atlantic (EA) pattern, with loadings of 0.69 for the De Martonne index and 0.67 for the Pinna index.

Fig. 9 depicts the spatial distribution of the scores of the first three rotated PCs of the continentality indices. The results reveal a similar spatial variability for both JCI and MOI, albeit with a reversed sign. For the first PC, the largest scores were mainly distributed over the Fertile Crescent, north-western Iran and the southern Arabian Peninsula and Algeria. Given the positive coupling between continentality conditions and circulation patterns originating over the Atlantic Ocean for this PC (Fig. 8), it can be implied that the anomalous years during the positive phase 
of these circulation patterns can enhance continental conditions over these particular areas. This finding was confirmed when we assessed temporal changes in the Atlantic circulation patterns that contribute significantly to the evolution of continentality and aridity over the MENA region. As illustrated in Fig. 10, a statistically significant trend was found for the majority of these patterns (e.g., AMM, AMO, ASTSST, NTA and TSA) over the period 1960-2013. Ghasemi and Khalili (2006) found a significant correlation between the westerly winds originating from the warm Atlantic regions and anomalously warm temperatures over Iran during the period 19512000. For the second PC, it seems that the continentality conditions over the Sahara responds differently to circulation patterns, with respect to other areas in the MENA region. More continental climate over the Sahara appeared to be coupled with the positive phase of the Scandinavian (SCA) and the Southern Oscillation (SO) patterns, and the negative mode of the Bombay SLP anomaly (BOMBAY) as well as the Eastern Atlantic-Western Russian (EAWR) patterns: a picture that is completely reversed for the Iranian territory. The spatial distribution of the scores for the third PC suggests a clear spatial contrast between the Nile Basin on one hand and the Arabian Peninsula and the Ethiopian Highlands on the other. These spatial variations were specific only to JCI.

The spatial variability of aridity-circulation dependency, as represented by the scores of the first three PCs, is shown in Fig. 11. The results revealed that some component scores varied considerably across regions, suggesting that there was a different regional response of aridity to circulation patterns. The first PC shows a clear gradient from south (most humid) to north (most arid) regions, while the second PC distinguishes markedly between the Sahara and the Nile Basin on one hand and the Arabian Peninsula, Iran and the Fertile Crescent on the other hand. The third PC did not reveal any significant spatial differences between the MENA sub-regions, except for Morocco, which showed higher scores than other regions.

\section{CONCLUSIONS}

A comprehensive assessment of the spatial and temporal changes in a range of climatic indices that determine the continentality and aridity status over the Middle East and North Africa (MENA) region was undertaken. Based on temperature and precipitation data from CRU TS3.22, two continentality (JCI and MOI) and two aridity (De Martonne and Pinna) indices were 
computed for the period 1960-2013. Results suggested a high consistency among the continentality indices, as both JCI and MOI were generally reasonable in representing climate continentality across the region. Despite the aridity indices using different classification schemes, their spatial distributions were comparable, suggesting the applicability of both to the MENA region. Temporal changes in the continentality and aridity indices were also examined over a 54-year period (1960-2013). Results suggested a statistically significant increase in the continental conditions, but with considerable regional differences. The most rapid changes were found in the Nile Basin, the Fertile Crescent and the Ethiopian Highlands, while smaller changes occurred over the Arabian Peninsula, Sahara and Iran. For aridity indices, results showed an increase in aridity conditions, though being statistically insignificant for the majority of the study domain.

In the context of global warming, it is important to understand how climate change might affect continentality and aridity indicators in the MENA region. We employed the principal components analysis (PCA) to identify the circulation patterns that control the spatial distribution of aridity and continentality across the study domain. Results showed that the response of continentality and aridity to circulation patterns differs spatially, confirming a major influence of circulations originating over the Atlantic Ocean, compared to those of the Mediterranean Sea and the Indian Ocean. Thus, further characterization of the mechanisms and associations between the Atlantic modes variability and climate aridity and continentality is required, as too is determining the impact of seasonality on these climate responses.

Given the sensitivity of the arid and semi-arid zones of the mid-latitudes to changes in the climate system, the results of this work provide insights into the possible impacts of global warming over the MENA region. Given that the study domain includes countries whose people are uniquely vulnerable not only to drought and other natural disasters, but also to economic and social changes, recent climate changes could increase the likelihood of political instability and national conflicts, with resulting economic and social consequences. Our work presents the first attempt at a detailed and regionally-broad assessment of recent changes in climate continentality and aridity over the MENA region. Better understanding these climate driven responses is 
needed to improve the longer-term management of water resources, food production and energy supply and distribution sectors.

Acknowledgements: Research reported in this publication was supported by the King Abdullah University of Science and Technology (KAUST), Saudi Arabia. We wish to thank the Climate Research Unit (CRU) at the University of East Angelia (UK) for providing their data.

\section{LITERATUTE CITED}

Almazroui M, Dambul R, Islam N, and Jones PJ (2015) Atmospheric circulation patterns in the Arab region and its relationships with Saudi Arabian surface climate: A preliminary assessment, Atmos. Res., 161-162: 36-51.

Almazroui M, Nazrul Islam M, Jones PJ, Athar H, and Rahman MA (2012) Recent climate change in the Arabian Peninsula: Seasonal rainfall and temperature climatology of Saudi Arabia for 1979-2009, Atmos. Res., 111: 29-45.

Andrade C., and Corte Real J (2014) Spatial distribution of climate change indices in the Iberian Peninsula, ICNAAM conference, Volume 1648.

Baltas E (2007), Spatial distribution of climatic indices in northern Greece, Met. Apps., 14(1): 69-78.

Bannayana M, Sanjani S, Alizadeha A, Lotfabadi SS, and Mohamadianb A (2010) Association between climate indices, aridity index, and rainfed crop yield in northeast of Iran, Field Crops Res., 118: 105-114.

Berhane F, Zaitchik B, and Dezfuli A. (2014) Subseasonal analysis of precipitation variability in the blue Nile river basin. J. Climate, 27: 325-344.

Bhowmik AK. and Costa AC (2015) Representativeness impacts on accuracy and precision of climate spatial interpolation in data-scarce regions. Met. Apps, 22: 368-377.

Bindoff, N. L., et al. (2013). Detection and Attribution of Climate Change: from Global to Regional. Climate Change 2013: The Physical Science Basis. Contribution of Working Group I to the Fifth Assessment Report of the Intergovernmental Panel on Climate Change. T. F. Stocker, D. Qin, G.-K. Plattner et al. Cambridge, United Kingdom and New York, NY, USA, Cambridge University Press: 867-952.

Brázdil R, Chromá K, Dobrovolný P, and Tolasz R. (2009) Climate fluctuations in the Czech Republic during the period 1961-2005, Int.J.of Climatol., 29(2): 223-242.

Burke MP, Miguel E, Satyanath S, Dykema JA, and Lobell DB (2009) Warming increases the risk of civil war in Africa, PNAS, 106 (49): 20670-20674.

Croitoru A, Piticar A, Imbroane AM, and Burada DC (2013) Spatiotemporal distribution of aridity indices based on temperature and precipitation in the extra-Carpathian regions of Romania, Theor Appl Climatol, 112(3-4): 597-607.

Deng L, McCabe MF, Stenchikov G, Evans JP, and Kucera PA (2015) Simulation of FlashFlood-Producing Storm Events in Saudi Arabia Using the Weather Research and Forecasting Model. , J. Hydrometeorology, 16(615-630): 615-630.

Deniz A, Toros H, and Incecik S. (2011) Spatial variations of climate indices in Turkey, Int. J. of Climatol., 31(3): 394-403. 
Deser C, Timlin, MA (1997) Atmosphere-Ocean Interaction on Weekly Timescales in the North Atlantic and Pacific. Journal of Climate, 10, 3, 393-408.

Diro GT, Grimes DIF, and Black E. (2011) Teleconnections between Ethiopian summer rainfall and sea surface temperature: Part I. Observation and modelling. Climate Dyn., 37: 103119.

Donat MG et al. (2014) Changes in extreme temperature and precipitation in the Arab region: long-term trends and variability related to ENSO and NAO, Int. J. of Climatol., 34(3): 581-592.

El Kenawy A, López-Moreno J, Vicente-Serrano S, and Mekld M. (2009) Temperature trends in Libya over the second half of the 20th century, Theor Appl Climatol, 98(1-2): 1-8.

El Kenawy A, López-Moreno J, and Vicente-Serrano S (2013) Summer temperature extremes in northeastern Spain: spatial regionalization and links to atmospheric circulation (19602006), Theor Appl Climatol, 113(3-4): 387-405.

El Kenawy A, McCabe MF, Stenchikov G, and Raj J (2014) Multi-Decadal Classification of Synoptic Weather Types, Observed Trends and Links to Rainfall Characteristics over Saudi Arabia, Frontiers in Environmental Science, 2, doi:10.3389/fenvs.2014.00037.

El Kenawy A and McCabe MF (2015) A multi-decadal assessment of the performance of gaugeand model-based rainfall products over Saudi Arabia: climatology, anomalies and trends, Int. J. of Climatol., doi:10.1002/joc.4374.

Enfield DB, Mestas-Nuñez AM, Mayer DA and Cid-Serrano L (1999) How ubiquitous is the dipole relationship in tropical Atlantic sea surface temperatures? J. Geophys. Res., 104, 7841-7848.

Enfield DB, Mestas-Nuñez AM and Trimble PJ (2001) The Atlantic Multidecadal Oscillation and its relation to rainfall and river flows in the continental U.S, Geophys. Res. Lett., 28(10), 2077-2080.

Gavilán R (2005) The use of climatic parameters and indices in vegetation distribution. A case study in the Spanish Sistema Central, Int J Biometeorol, 50(2): 111-120.

Giorgi F (2006) Climate change hot-spots, Geophys. Res. Lett., 33, L08707, doi:10.1029/2006GL025734.

Glickman TS (2000) Glossary of Meteorology, American Mteorological Society, 2nd edition, 850pp.

Harris I, Jones PD, Osborn TJ, and Lister DH (2014) Updated high-resolution grids of monthly climatic observations - the CRU TS3.10 Dataset, Int. J. of Climatol., 34(3): 623-642.

Hasanean HM and Basset HA (2006) Variability of summer temperature over Egypt, Int. J. of Climatol., 26(12): 1619-1634.

Jones PD, Jónsson T and Wheeler D (1997) Extension to the North Atlantic Oscillation using early instrumental pressure observations from Gibraltar and South-West Iceland. Int. J. Climatol. 17: 1433-1450.

Jones PD, Horton EB, Folland CK, Hulme M, Parker DE, and Basnett TA (1999) The Use of Indices to Identify Changes in Climatic Extremes, Clim. Change, 42(1): 131-149.

Kafle H and Bruins H (2009) Climatic trends in Israel 1970-2002: warmer and increasing aridity inland, Clim. Change, 96(1-2): 63-77.

Karl TR, Knight RW, and Baker B (2000) The record breaking global temperatures of 1997 and 1998: Evidence for an increase in the rate of global warming?, Geophys. Res.Lett., 27(5): 719-722. 
Kleinebecker T, Hölzel N, and Vogel A (2007) Gradients of continentality and moisture in South Patagonian ombrotrophic peatland vegetation, Folia Geobot, 42(4): 363-382.

Levin NE, Zipser EJ, and Cerling TE (2009) Isotopic composition of waters from Ethiopia and Kenya: Insights into moisture sources for eastern Africa. J. Geophys. Res., 114: D23306, doi:10.1029/2009JD012166.

Maliva R, and Missimer T (2012) Aridity and drought, in Arid Lands Water Evaluation and Management, Springer, Berlin.

Martin-Vide J, and Lopez-Bustins JA (2006) The Western Mediterranean Oscillation and rainfall in the Iberian Peninsula, Int. J. of Climatol., 26(11): 1455-1475.

Minetti JL (1989) Continentality indices: methodological revision and proposition, Erdkunde, 43(1): 51-58.

Nasrallah H, and Balling R (1993) Spatial and temporal analysis of Middle Eastern temperature changes, Clim. Change, 25(2): 153-161.

Nazemosadat MJ, and Cordery I (2000) On the relationships between ENSO and autumn rainfall in Iran, Int. J. of Climatol., 20(1): 47-61.

Pal, J. S. and Eltahir, E. A. B. (2016). Future temperature in southwest Asia projected to exceed a threshold for human adaptability. Nature Clim. Change, 6(2), 197-200.

Palutikof JP, Conte M, Casimiro Mendes J, Goodess CM, Espirito Santo F (1996). Climate and climate change. In: Brandt, C.J., Thornes, J.B., (eds) Mediterranean desertification and land use. John Wiley and Sons, London.

Qian C, and Zhou T (2014) Multidecadal Variability of North China Aridity and Its Relationship to PDO during 1900-2010, J. Climate, 27: 1210-1222.

Rahman K, Gorelick SM, Dennedy-Frank PJ, Yoon J, and Rajaratnam B (2015) Declining rainfall and regional variability changes in Jordan, Water Resour. Res., 51: 3828- 3835.

Rayner NA, Parker DE, Horton EB, Folland CK, Alexander LV, Rowell DP, Kent EC, and Kaplan A (2003) Global analyses of sea surface temperature, sea ice, and night marine air temperature since the late nineteenth century, J. of Geophys. Res.: Atmospheres, 108(D14): doi:10.1029/2002JD002670.

Raziei T, Bordi I, Santos JA, and Mofidi A (2013) Atmospheric circulation types and winter daily precipitation in Iran, Int. J. of Climatol., 33(9): 2232-2246.

Raziei T, Mofidi A, Santos JA, and Bordi I (2012) Spatial patterns and regimes of daily precipitation in Iran in relation to large-scale atmospheric circulation, Int. J. of Climatol., 32(8): 1226-1237.

Segele ZT and Lamb PJ (2005) Characterization and variability of Kiremt rainy season over Ethiopia. Meteor. Atmos. Phys., 89: 153-180.

Shahid S (2008) Spatial and temporal characteristics of droughts in the western part of Bangladesh, Hydrolo.Process., 22(13): 2235-2247.

Shifteh Somee B, Ezani A, Tabari H (2013) Spatiotemporal trends of aridity index in arid and semi-arid regions of Iran, Theor Appl Climatol, 111(1-2): 149-160.

Tabari H, Talaee PH (2011) Temporal variability of precipitation over Iran: 1966-2005, J. Hydrology, 396(3-4): 313-320.

Tabari H, Aghajanloo MB (2013) Temporal pattern of aridity index in Iran with considering precipitation and evapotranspiration trends, Int. J. of Climatol., 33(2): 396-409.

Tabari H, Hosseinzade T, Mousavi P, Nadushani SS, Willems P, Marchetoo A (2014) A survey of Temperature and precipitation based aridity indices in Iran, Quaternarly International: $1-9$. 
Tanarhte M, Hadjinicolaou P, Lelieveld J (2012) Intercomparison of temperature and precipitation data sets based on observations in the Mediterranean and the Middle East, J. of Geophy.Res.: Atmospheres, 117(D12): doi:10.1029/2011JD017293.

Trenberth, KE (2011) Changes in precipitation with climate change, Climate Res., 47-123.

UNEP (United Nations Environment Programme) (1997), World atlas of desertification 2nd ed. UNEP, London.

Vicente-Serrano SM, Beguería S, López-Moreno JI, El Kenawy A, Angulo-Martínez M (2009) Daily atmospheric circulation events and extreme precipitation risk in northeast Spain: Role of the North Atlantic Oscillation, the Western Mediterranean Oscillation, and the Mediterranean Oscillation, J.of Geophys. Res.: Atmospheres, 114(D8): doi:10.1029/2008JD011492.

Vicente-Serrano SM, Chura O, López-Moreno JI, Azorin-Molina C, Sanchez-Lorenzo A, Aguilar E, Moran-Tejeda E, Trujillo F, Martínez F, Nieto JJ (2014) Spatio-temporal variability of droughts in Bolivia: 1955-2012, Int. J. of Climatol., doi:10.1002/joc.4190.

Vicente-Serrano, SM, Cabello, D, Tomás-Burguera, M, Martín-Hernández, N, Beguería, S, Azorin-Molina, C, Kenawy, A (2015) Drought Variability and Land Degradation in Semiarid Regions: Assessment Using Remote Sensing Data and Drought Indices (19822011). Remote Sens., 7, 4391-4423.

Wilks D (2011) Statistical Methods in the Atmospheric Sciences, ACADEMIC PRESS, Cornell University, Ithaca, New York, U.S.A.

Zambakas J (1992) General climatology, Department of Geology, National \& Kapodistrian University of Athens, Athens.

Zarghamia M, Abdia A, Babaeianb I, Hassanzadeha Y, Kananic R (2011) Impacts of climate change on runoffs in East Azerbaijan, Iran, Glob.and Planet. Change, 78(3-4): 137-146.

Zhang X, Harvey KD, Hogg WD, Yuzyk TR (2001) Trends in Canadian streamflow, Water Resources Research, 37(4), 987-998. 
739 Table 1: Climate classes according to four indices used in this study.

\begin{tabular}{ll} 
JCI & \\
Climate types & Index values \\
\hline Marine & $0 \leq \mathrm{I}<33$ \\
Continental & $33 \leq \mathrm{I}<66$ \\
Exceptionally continental & $66 \leq \mathrm{I}<100$ \\
\hline
\end{tabular}

\begin{tabular}{ll} 
MOI & \\
Climate types & Index values \\
\hline Continental & $\mathrm{I}<2$ \\
Sub-oceanic & $2 \leq \mathrm{I}<3$ \\
Oceanic & $3 \leq \mathrm{I}$ \\
\hline
\end{tabular}

\begin{tabular}{lll} 
De Martonne & & \\
Climate types & Index values \\
\hline Arid & & \\
Semi-arid & & \\
Mediterranean & & \\
Semi-humid & $20 \leq \mathrm{I}<20$ & \\
Humid & $24 \leq \mathrm{I}<28$ & \\
Very humid & $28 \leq \mathrm{I}<35$ \\
Extremely humid & $35 \leq \mathrm{I} \leq 55$ \\
\hline
\end{tabular}


Table 2: List of the circulation patterns used in this study.

\begin{tabular}{|c|c|c|}
\hline Acronym & Index description & Reference \\
\hline AMM & Atlantic Merditional Mode & Chiang et al., 2004 \\
\hline AMO & Atlantic Multidecadal Oscillation & Enfield et al., 2001 \\
\hline BOMBAY & Bombay SLP anomaly pattern & Berhane et al., 2014 \\
\hline EA & East Atlantic & http://www.cpc.noaa.gov/data/teledoc/telecontents.shtm \\
\hline EAWR & Eastern Atlantic-Western Russian pattern & NOAA Climate Prediction Center (CPC) \\
\hline $\begin{array}{l}\text { El Niño } \\
1+2\end{array}$ & Niño1+2 SST anomaly index & Rayner et al., 2003 \\
\hline MJO-1 & Monthly Madden Julian Oscillation index & http://www.esrl.noaa.gov/psd/mjo/mjoindex/ \\
\hline MO & Mediterranean Oscillation index & Palutikof et al. (1996) \\
\hline SCA & Scandinavian pattern & http://www.cpc.noaa.gov/data/teledoc/telecontents.shtm \\
\hline SO & Southern Oscillation index & NOAA Climate Prediction Center (CPC) \\
\hline SR & Sahel Rainfall Index & http://jisao.washington.edu/data_sets/sahel/ \\
\hline $\mathrm{TN}$ & Trans Niño index & Rayner et al., 2003 \\
\hline TNA & Tropical North Atlantic Index & Enfield et al., 1999 \\
\hline TSA & Tropical Southern Atlantic (TSA) index & Enfield et al., 1999 \\
\hline WeMO & Western Mediterranean Oscillation index & Martin-Vide and Lopez-Bustins, 2006 \\
\hline
\end{tabular}




\begin{tabular}{lccllllll}
\hline & JCI & MOI & $\begin{array}{l}\text { Tmax } \\
\text { Summer }\end{array}$ & $\begin{array}{l}\text { Tmin } \\
\text { Winter }\end{array}$ & $\begin{array}{l}\text { Tmax } \\
\text { Warmest } \\
\text { Month }\end{array}$ & $\begin{array}{l}\text { Tmin } \\
\text { Coldest } \\
\text { month }\end{array}$ & De Martonne & Pinna \\
\hline Ethiopian Highlands & 0.55 & -0.24 & $\mathbf{0 . 2 6}$ & $\mathbf{0 . 1 1}$ & $\mathbf{0 . 2 0}$ & $\mathbf{0 . 1 1}$ & $\mathbf{- 0 . 5 6}$ & $\mathbf{- 0 . 1 9}$ \\
Fertile Crescent & $\mathbf{0 . 8 8}$ & $\mathbf{- 0 . 1 4}$ & $\mathbf{0 . 3 8}$ & 0.16 & $\mathbf{0 . 3 6}$ & 0.16 & $\mathbf{- 0 . 3 1}$ & $\mathbf{- 0 . 1 5}$ \\
African Horn & 0.57 & -0.10 & $\mathbf{0 . 1 1}$ & $\mathbf{0 . 1 0}$ & $\mathbf{0 . 0 9}$ & $\mathbf{0 . 1 0}$ & -0.12 & -0.02 \\
Iran & 0.51 & -0.08 & $\mathbf{0 . 3 8}$ & $\mathbf{0 . 2 5}$ & $\mathbf{0 . 3 9}$ & 0.21 & -0.26 & -0.13 \\
Morocco & 0.02 & 0.02 & $\mathbf{0 . 2 6}$ & $\mathbf{0 . 1 5}$ & $\mathbf{0 . 2 0}$ & $\mathbf{0 . 1 6}$ & -0.13 & -0.06 \\
Nile Basin & $\mathbf{1 . 0 9}$ & $\mathbf{- 0 . 2 0}$ & $\mathbf{0 . 4 0}$ & $\mathbf{0 . 4 0}$ & $\mathbf{0 . 4 1}$ & $\mathbf{0 . 3 7}$ & -0.12 & -0.06 \\
Arabian Peninsula & $\mathbf{0 . 8 9}$ & $\mathbf{- 0 . 1 4}$ & $\mathbf{0 . 2 6}$ & $\mathbf{0 . 1 9}$ & $\mathbf{0 . 2 8}$ & 0.11 & -0.08 & 0.01 \\
Sahara & $\mathbf{0 . 6 0}$ & $\mathbf{- 0 . 1 0}$ & $\mathbf{0 . 3 7}$ & 0.10 & $\mathbf{0 . 3 3}$ & 0.12 & -0.03 & -0.01 \\
\hline MENA & $\mathbf{0 . 6 9}$ & $\mathbf{- 0 . 1 2}$ & $\mathbf{0 . 3 3}$ & $\mathbf{0 . 2 0}$ & $\mathbf{0 . 3 1}$ & $\mathbf{0 . 1 8}$ & $\mathbf{- 0 . 1 5}$ & $\mathbf{- 0 . 0 5}$ \\
\hline
\end{tabular}

Table 3: Temporal evolution of the continentality and aridity indices over the period 1960-2013. The magnitudes of the trends given in bold are statistically significant at the 95\% level. The amount of changes in continentality and aridity indices is given in index units per decade, with the exception of MOI, which is given per century. Changes in temperature indices are given in ${ }^{\circ} \mathrm{C}$ per decade. 
815 Table 4. Pearson correlation coefficients calculated between seasonal and annual circulation 816 patterns. Statistically significant values at the 95\% level $(\mathrm{p}<0.05)$ are provided in bold. 817 Abbreviations of the patterns correspond to their description in Section 3.4.

818

\begin{tabular}{lcccc}
\hline Index & Winter (DJF) & Spring (MAM) & Summer (JJA) & Autumn (SON) \\
\hline AMM & $\mathbf{0 . 6 6}$ & $\mathbf{0 . 8 3}$ & $\mathbf{0 . 8 7}$ & $\mathbf{0 . 8 1}$ \\
AMO & $\mathbf{0 . 8 0}$ & $\mathbf{0 . 9 4}$ & $\mathbf{0 . 9 5}$ & $\mathbf{0 . 9 5}$ \\
ATSST & $\mathbf{0 . 8 1}$ & $\mathbf{0 . 9 3}$ & $\mathbf{0 . 9 0}$ & $\mathbf{0 . 9 4}$ \\
BOMBAY & $\mathbf{0 . 6 0}$ & $\mathbf{0 . 7 1}$ & $\mathbf{0 . 8 4}$ & $\mathbf{0 . 6 6}$ \\
EA & $\mathbf{0 . 4 9}$ & $\mathbf{0 . 7 5}$ & $\mathbf{0 . 8 3}$ & $\mathbf{0 . 5 4}$ \\
EASLP & $\mathbf{0 . 5 5}$ & $\mathbf{0 . 7 5}$ & $\mathbf{0 . 8 4}$ & $\mathbf{0 . 8 2}$ \\
EAWR & $\mathbf{0 . 4 7}$ & $\mathbf{0 . 4 5}$ & $\mathbf{0 . 6 6}$ & $\mathbf{0 . 6 4}$ \\
MJO_1 & $\mathbf{0 . 2 7}$ & $\mathbf{0 . 7 5}$ & $\mathbf{0 . 6 6}$ & $\mathbf{0 . 5 5}$ \\
MO & $\mathbf{0 . 2 7}$ & 0.22 & $\mathbf{0 . 7 5}$ & $\mathbf{0 . 5 1}$ \\
MPE & $\mathbf{0 . 5 2}$ & $\mathbf{0 . 4 6}$ & $\mathbf{0 . 4 0}$ & $\mathbf{0 . 6 9}$ \\
NAO & $\mathbf{0 . 4 8}$ & $\mathbf{0 . 6 1}$ & $\mathbf{0 . 5 3}$ & $\mathbf{0 . 5 7}$ \\
NINO1+2 & $\mathbf{0 . 4 7}$ & $\mathbf{0 . 8 7}$ & $\mathbf{0 . 9 6}$ & $\mathbf{0 . 8 7}$ \\
NTA & $\mathbf{0 . 8 1}$ & $\mathbf{0 . 9 4}$ & $\mathbf{0 . 9 4}$ & $\mathbf{0 . 8 7}$ \\
SCA & $\mathbf{0 . 3 3}$ & $\mathbf{0 . 5 5}$ & $\mathbf{0 . 5 9}$ & $\mathbf{0 . 4 5}$ \\
SO & $\mathbf{0 . 4 8}$ & $\mathbf{0 . 8 4}$ & $\mathbf{0 . 8 0}$ & $\mathbf{0 . 8 2}$ \\
SR & $\mathbf{0 . 7 5}$ & $\mathbf{0 . 4 9}$ & $\mathbf{0 . 3 9}$ & $\mathbf{0 . 6 5}$ \\
TNA & $\mathbf{0 . 7 7}$ & $\mathbf{0 . 9 0}$ & $\mathbf{0 . 9 3}$ & $\mathbf{0 . 8 4}$ \\
TSA & $\mathbf{0 . 6 5}$ & $\mathbf{0 . 8 8}$ & $\mathbf{0 . 9 3}$ & $\mathbf{0 . 7 8}$ \\
WeMO & $\mathbf{0 . 4 0}$ & -0.02 & 0.26 & 0.09 \\
\hline
\end{tabular}

819

820

821

822

823

824 


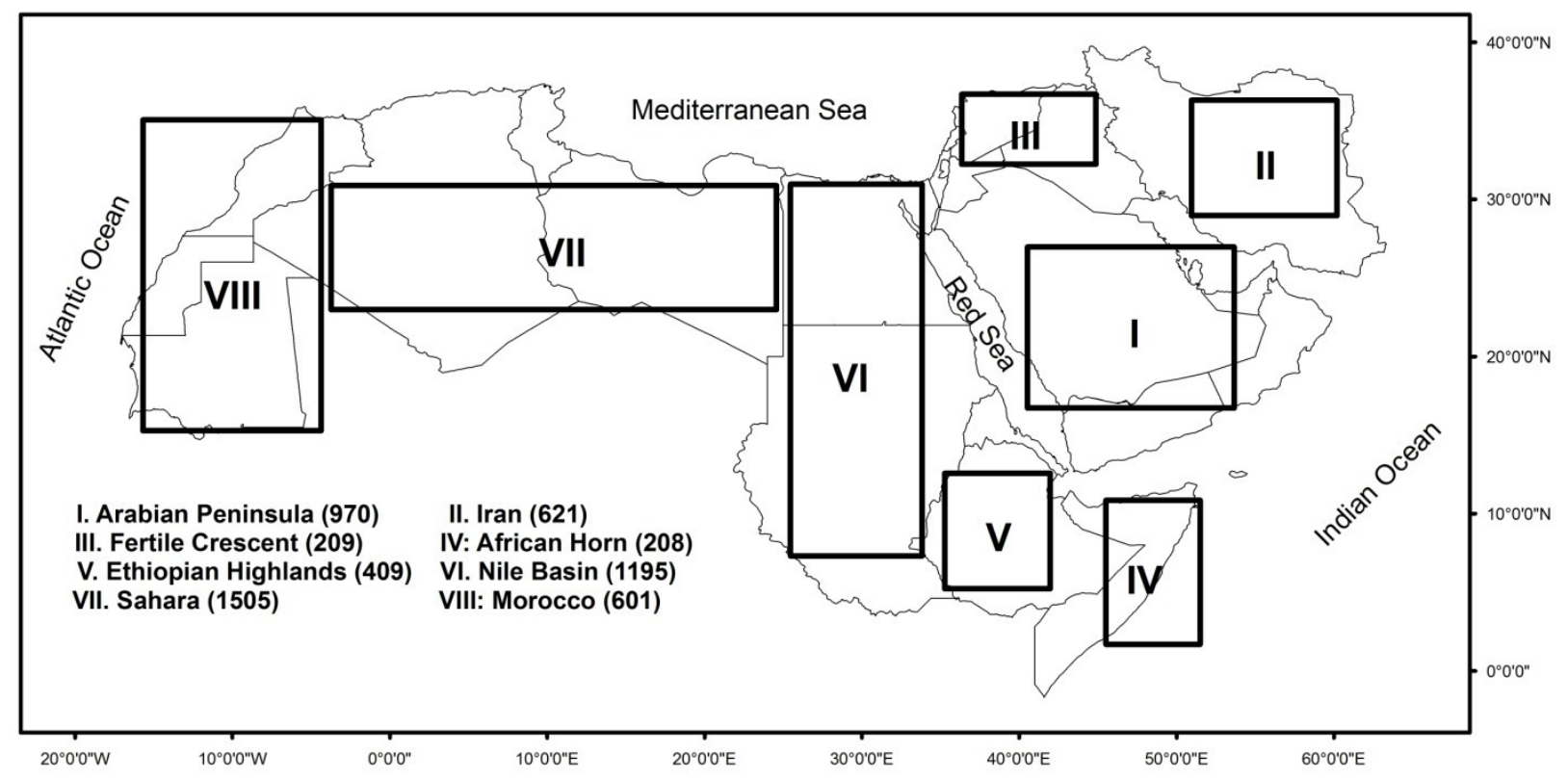

826 Fig. 1: Location of the Middle East and North Africa (MENA) region and the prescribed subdivisions. Bracketed values in the legend represent the number of data grid points corresponding to each sub-region. 

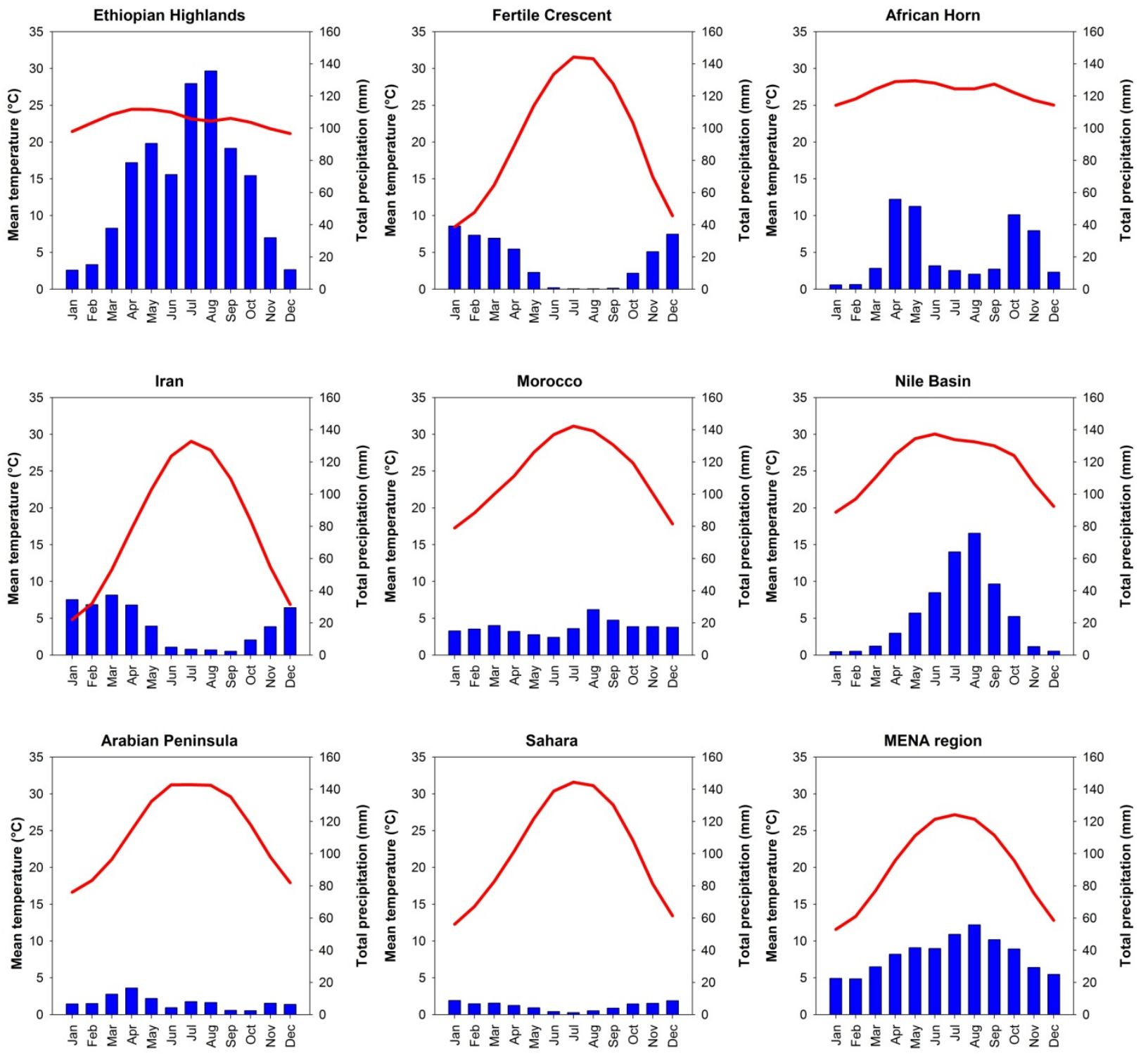

Fig. 2: Seasonal cycle of temperature and precipitation across the eight zones of the MENA region. Monthly averages of temperature and rainfall totals were computed for the period 19602013 using CRU (TS3.22 version) data. 

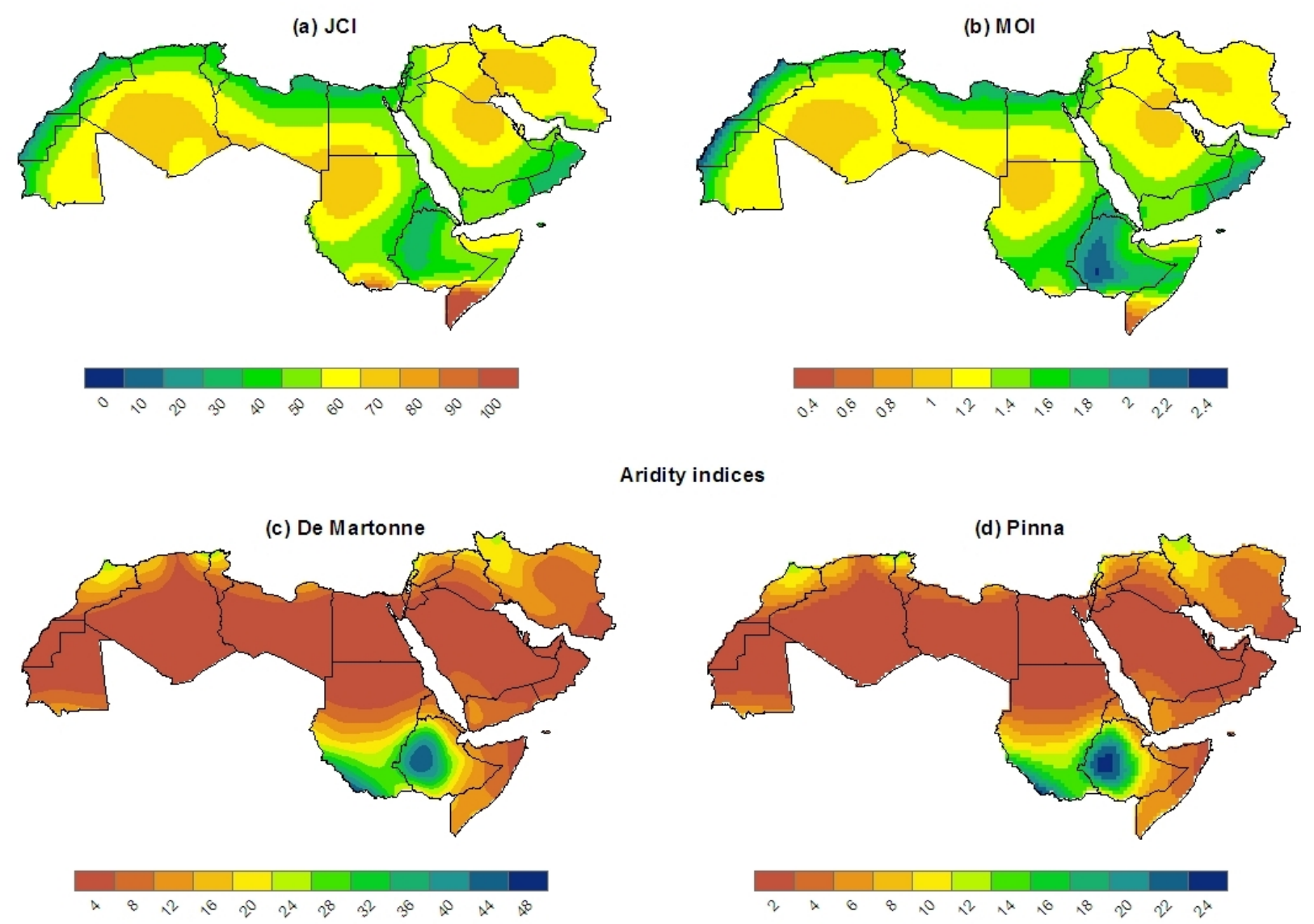

Aridity indices

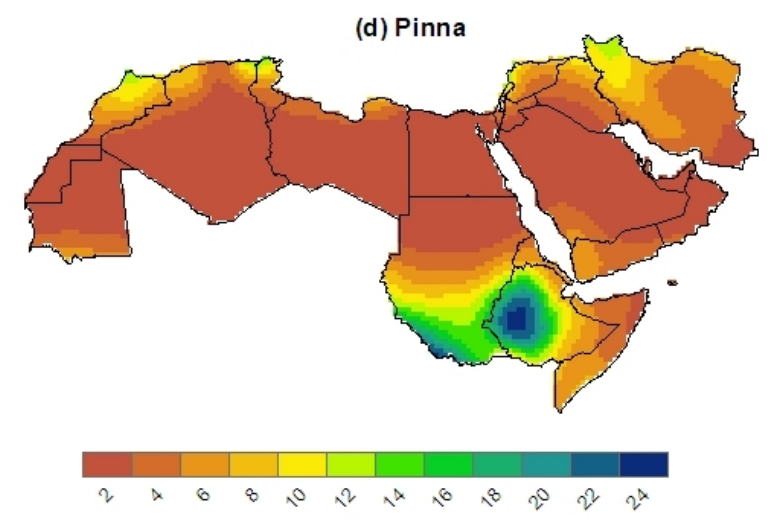

842 Fig. 3: Spatial distribution of the continentality: (a) JCI and (b) MOI and aridity: (c) De 843 Martonne and (d) Pinna values in the MENA region, averaged for the period from 1960 to 2013. 

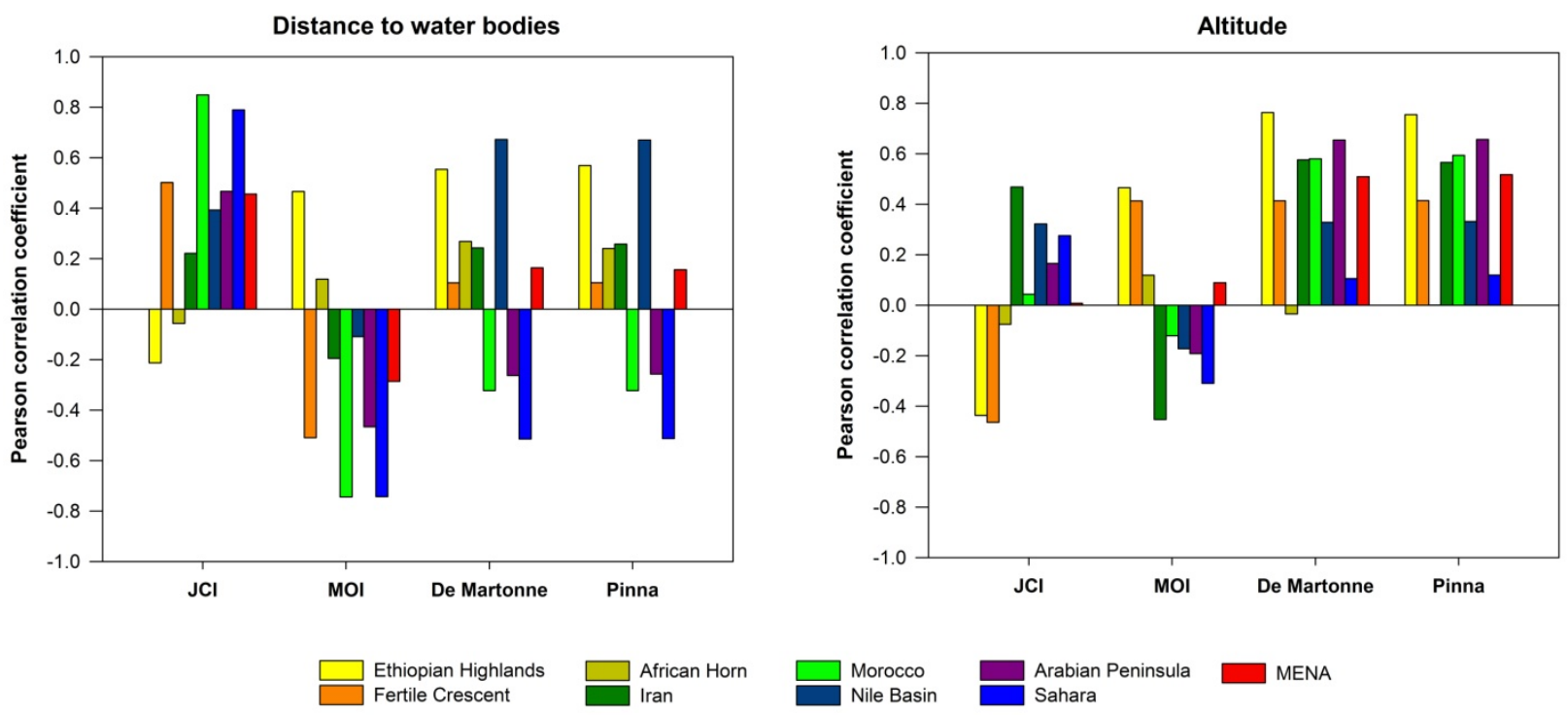

861

862

863

864

865

866

867

868

869

870

871

872

873

Fig. 4: The spatial Pearson correlation coefficients between the continentality and aridity index values (averaged for the period 1960-2013) and distance to the nearest water body (left) and altitude (right). 

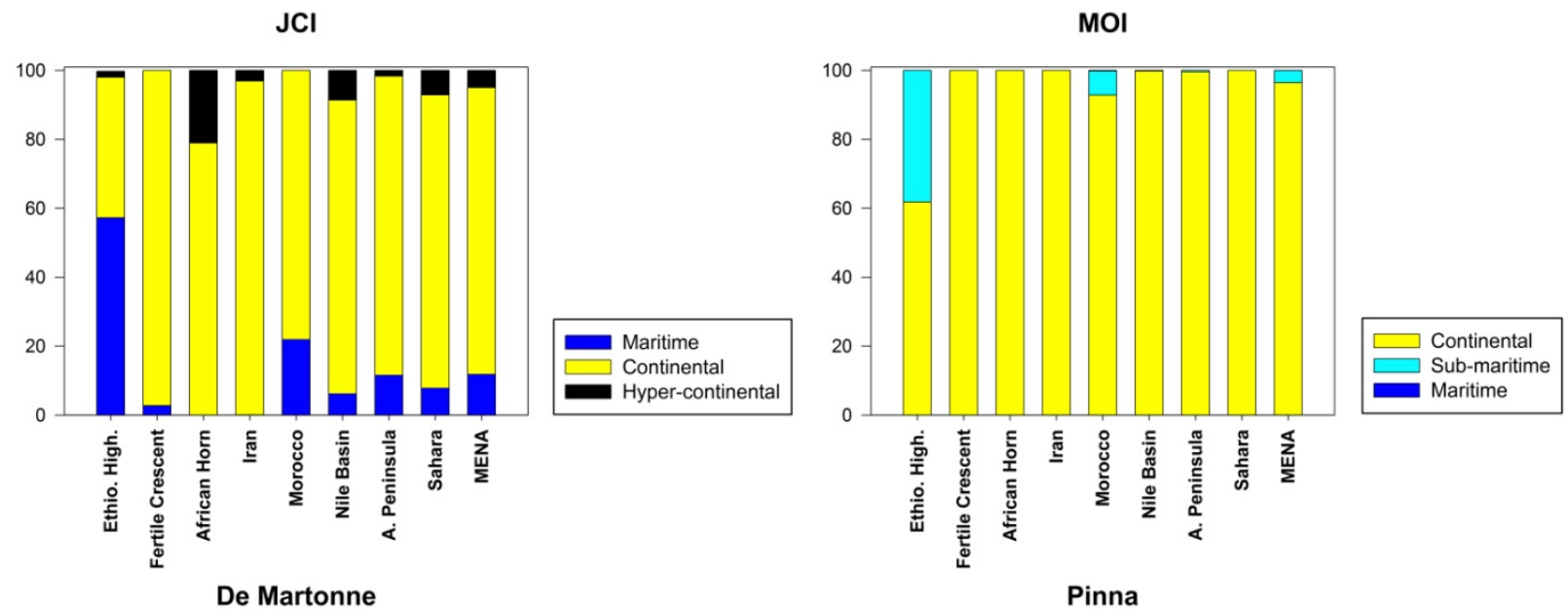

874

875

876

877

878

879

880

881

882

883

884

0

881

883
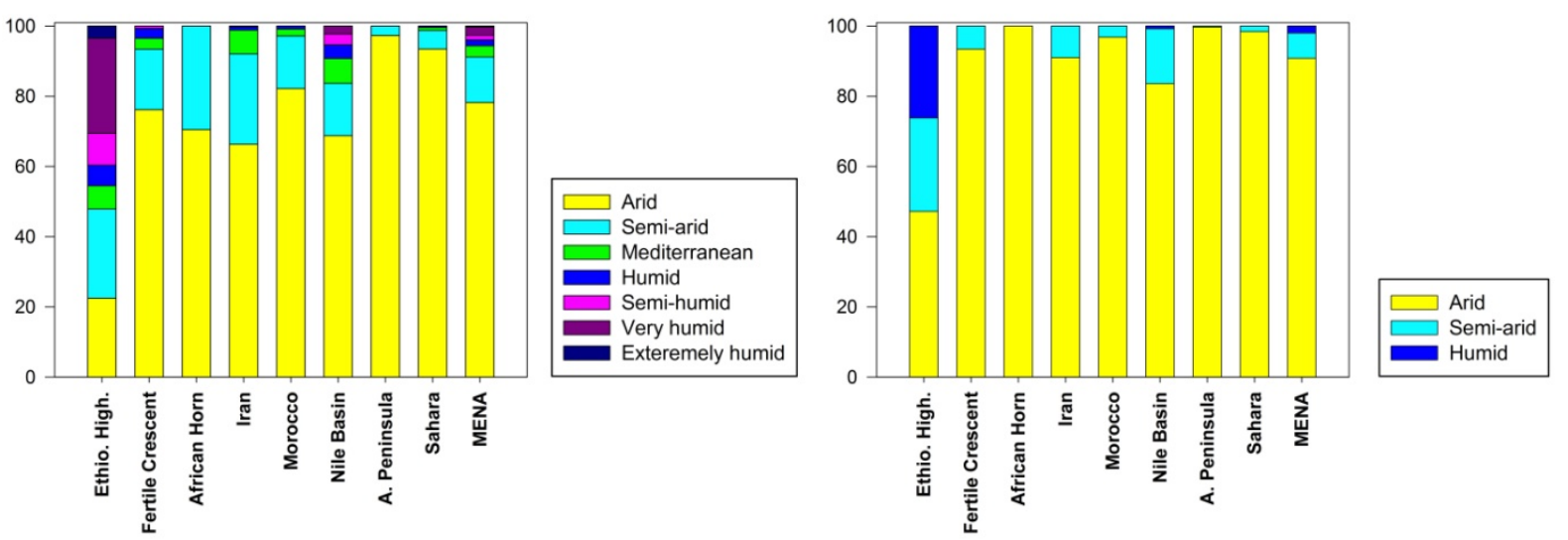

Fig. 5: The areal proportion represented by each climate class following the classification scheme of each continentality and aridity index. 


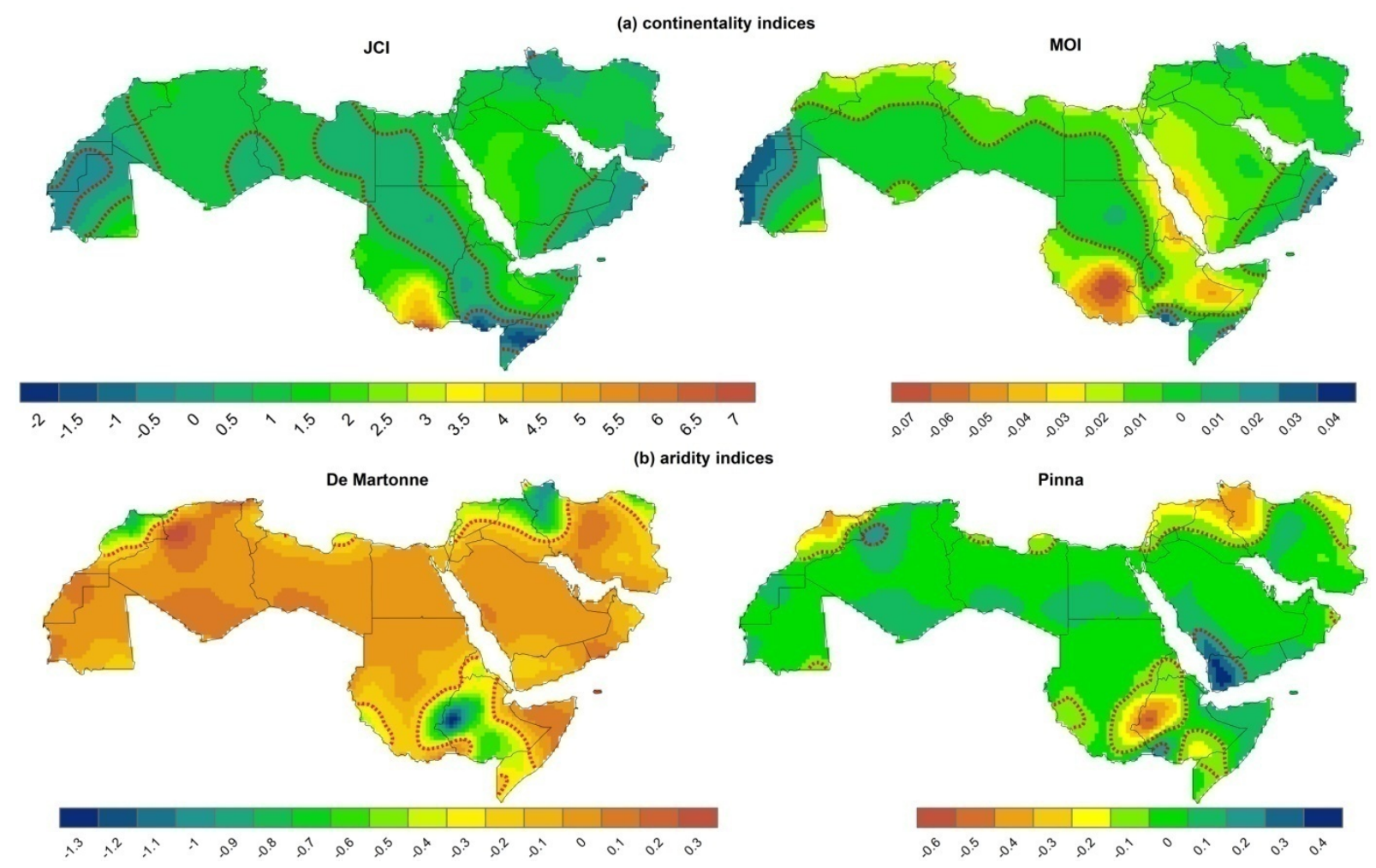

Fig. 6: Spatial distribution of the amount of change (per decade) in the index values over the period 1960-2013. The dotted red lines define the contoured areas where trends were statistically significant at the $95 \%$ significance level.

890

891 
(a) Relative change (\%)
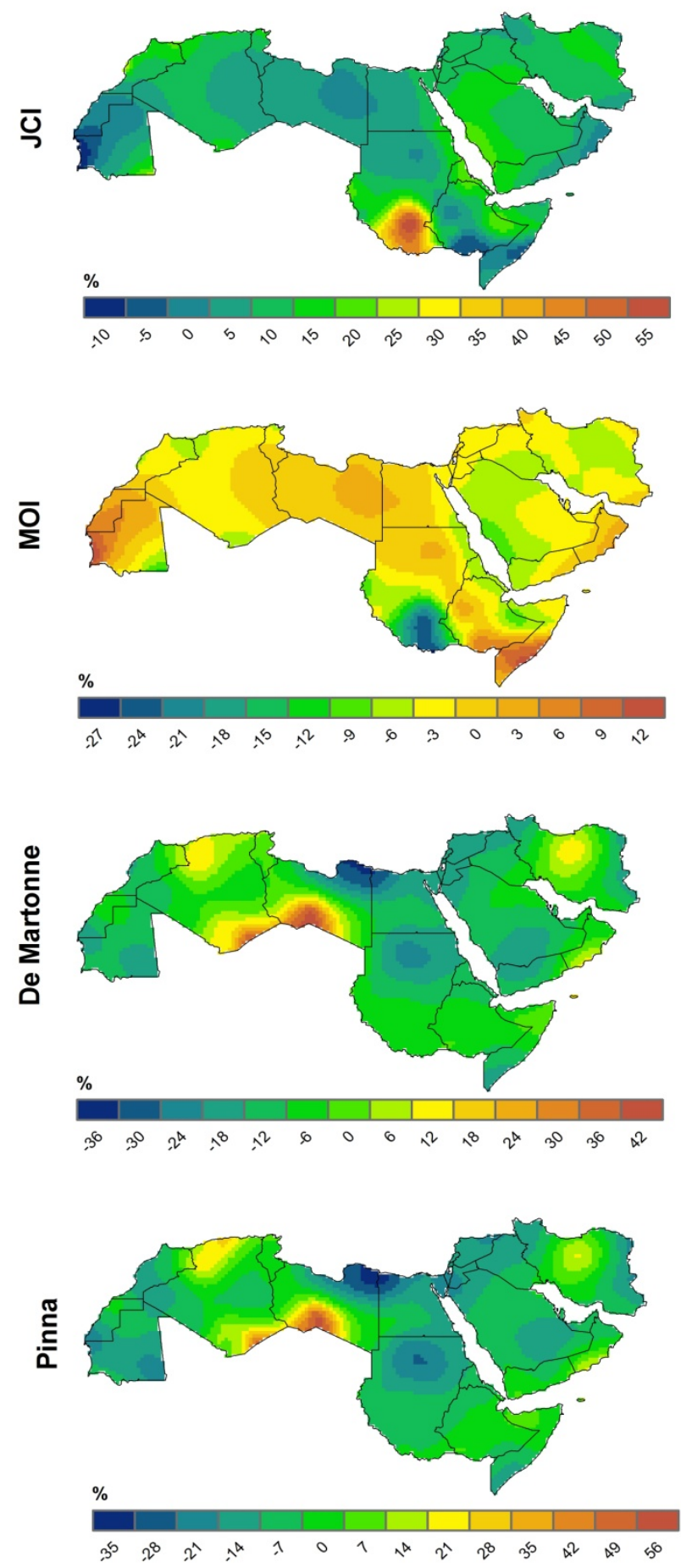

(a) Shift in climate class
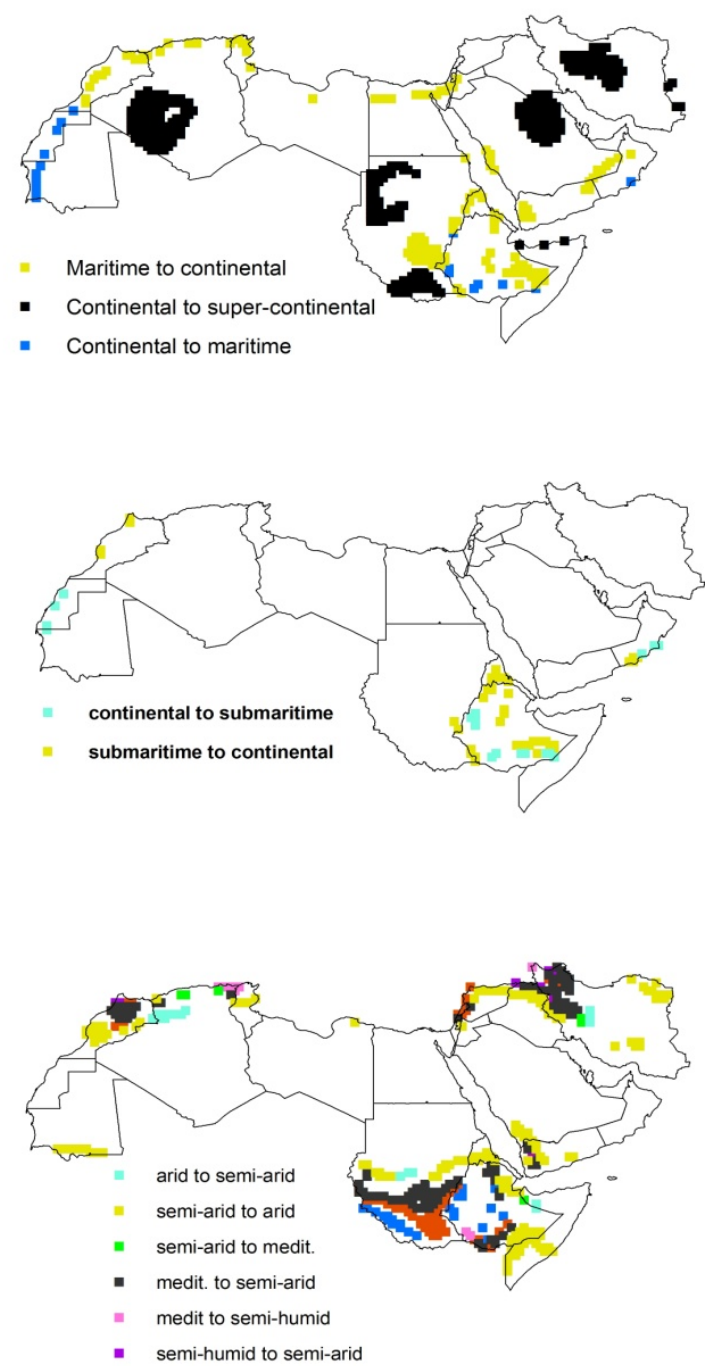

- semi-humid to semi-arid

- semi-humid to medit.

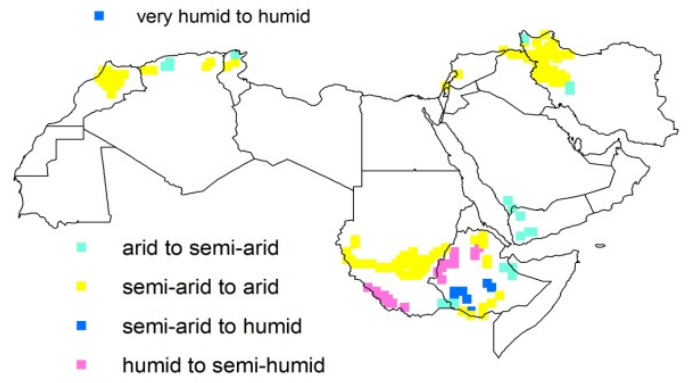

Fig. 7: Spatial distribution of the relative change (\%) in the continentality and aridity values (left panels) and shifts in their climate class (right panels). Both relative changes and shifts in the climate class were calculated using the difference between the values of continentality and aridity values in the first decade and the last decade of the study period (1960-2013). 

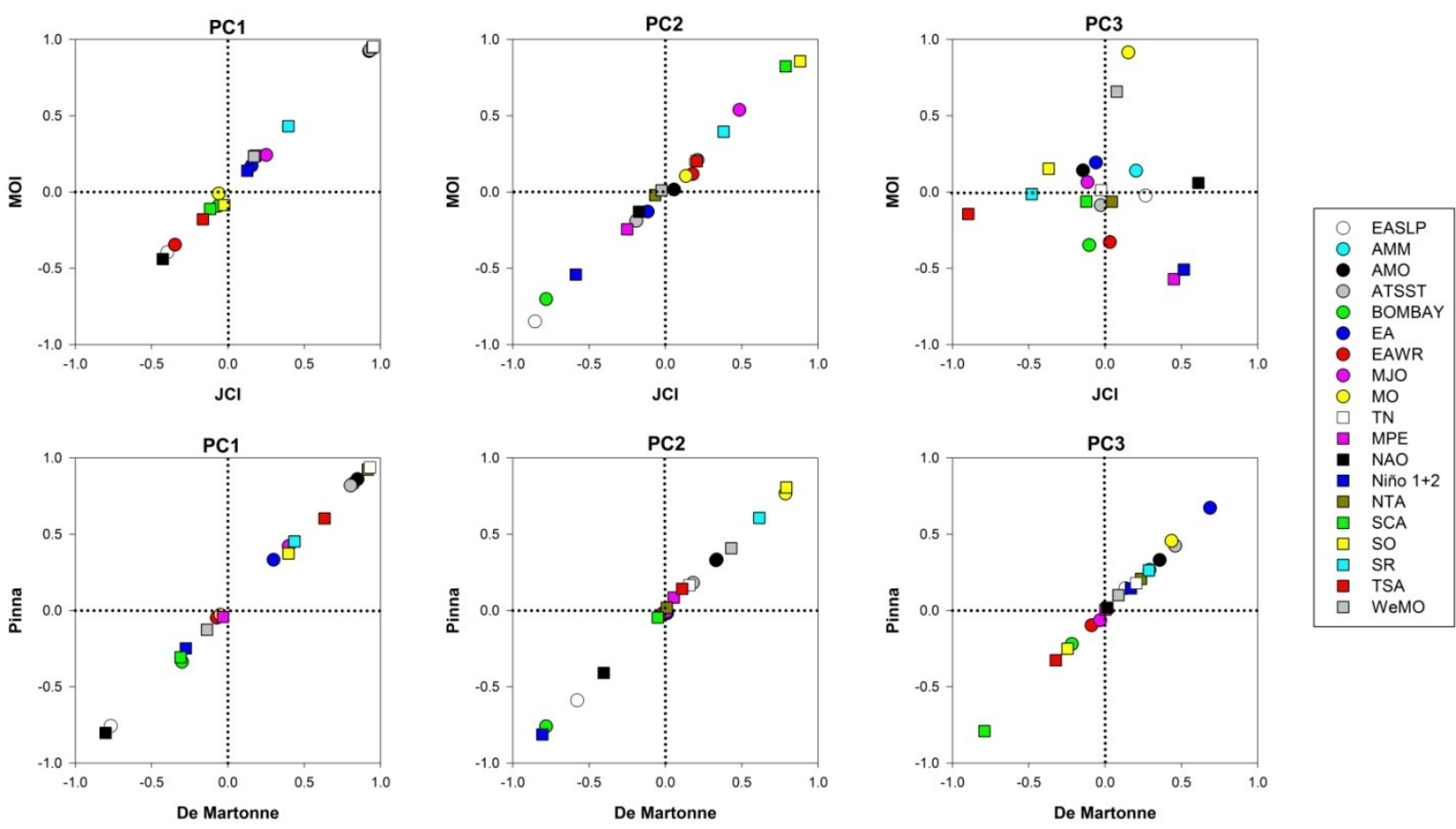

Fig. 8: Factor loadings along the first three principal components of each of the investigated 919 continentality and aridity indices. 

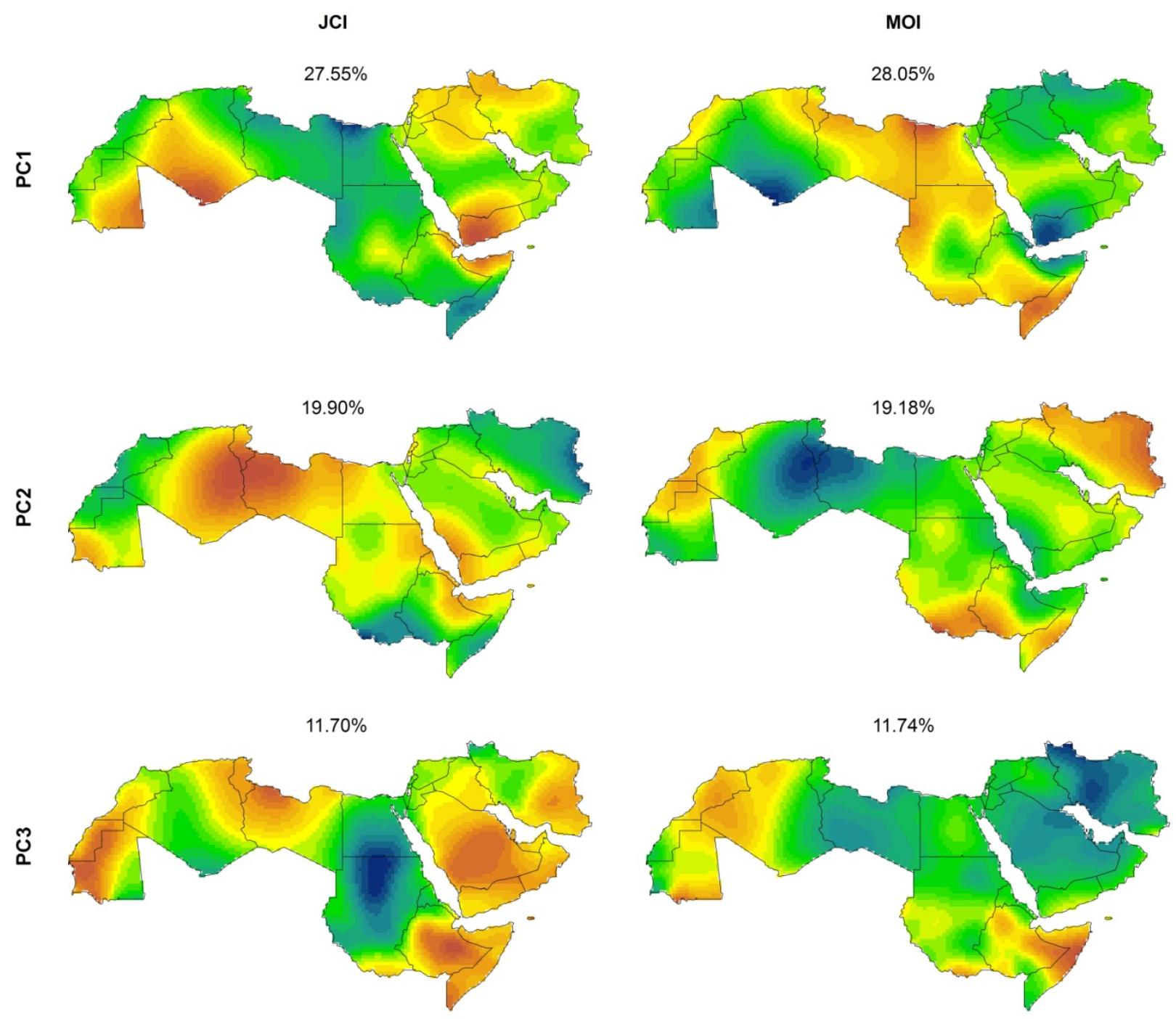

932 Fig. 9: Spatial distribution of the scores corresponding to the first three principal components of each continentality index. Percentages refer to the amount of variance explained by each component, as revealed by the PCA analysis. 

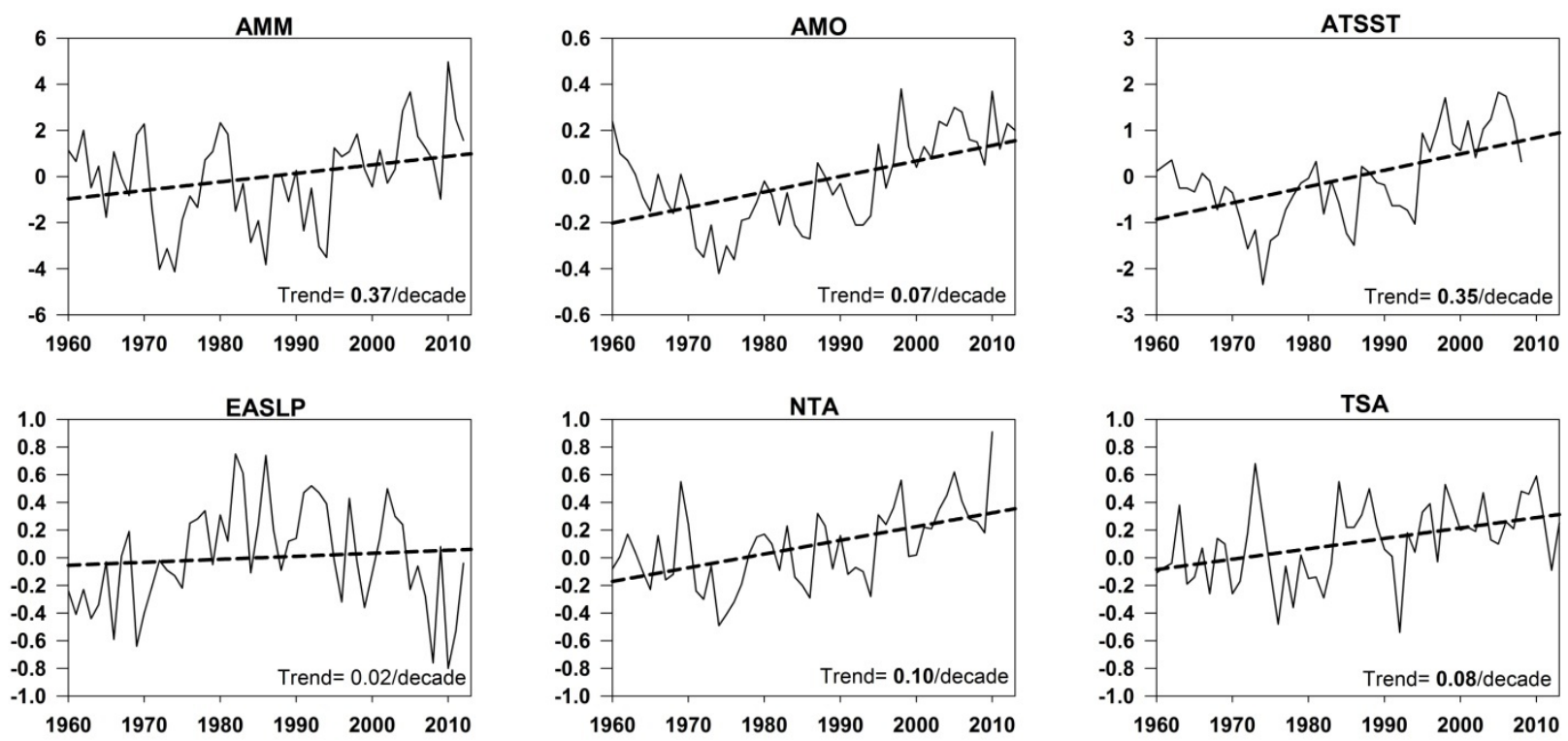

941

942

943

944

945

946

947

948

949

950

951

952

953

954

955

956

957

958

959

960

961

962

963

964

965

966

967

968

969

970

971

972

Fig. 10: Temporal evolution (1960-2013) of the circulation patterns that contribute significantly to continentality and aridity variations across the MENA region. Bold lines refer to the fitted regression line. The magnitudes of trends given in bold are statistically significant at the $95 \%$ level $(\mathrm{p}<0.05)$. 
(a) De Martonne
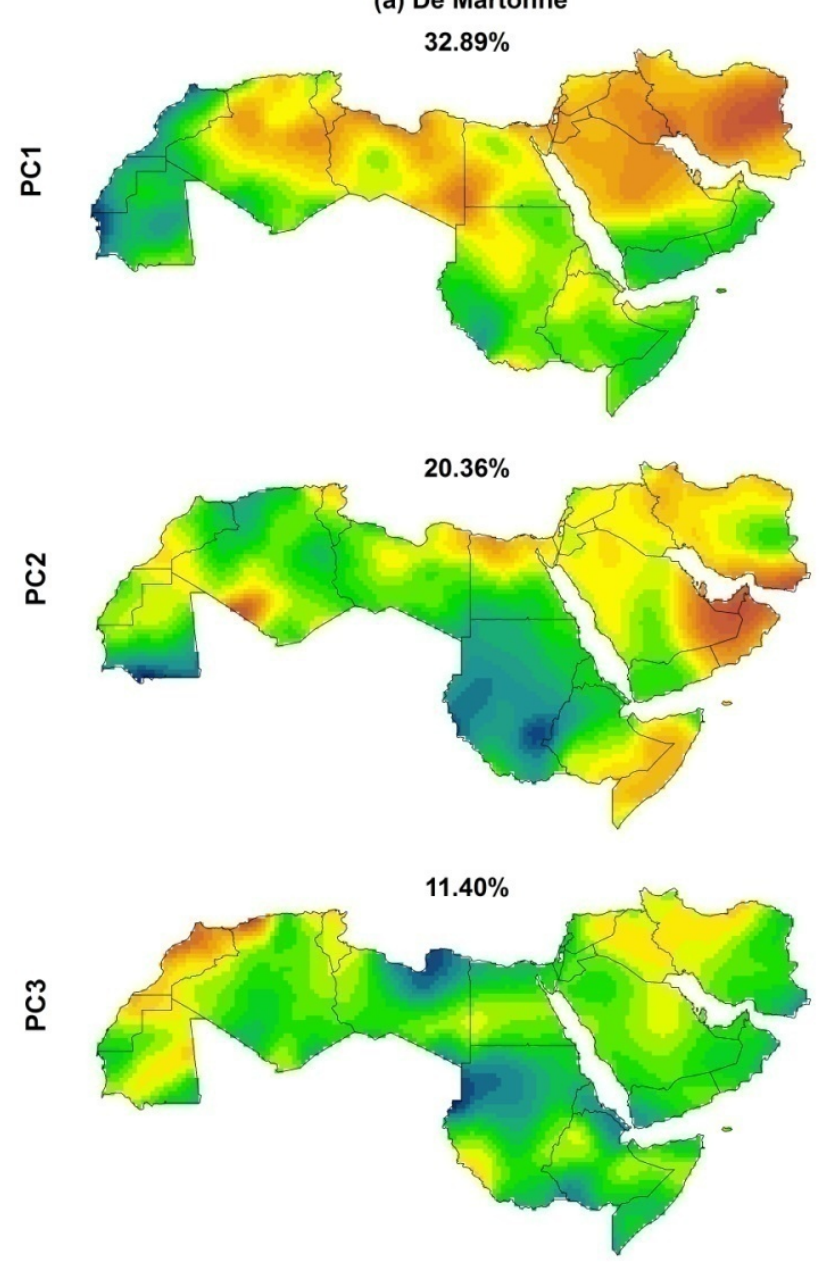

(b) Pinna
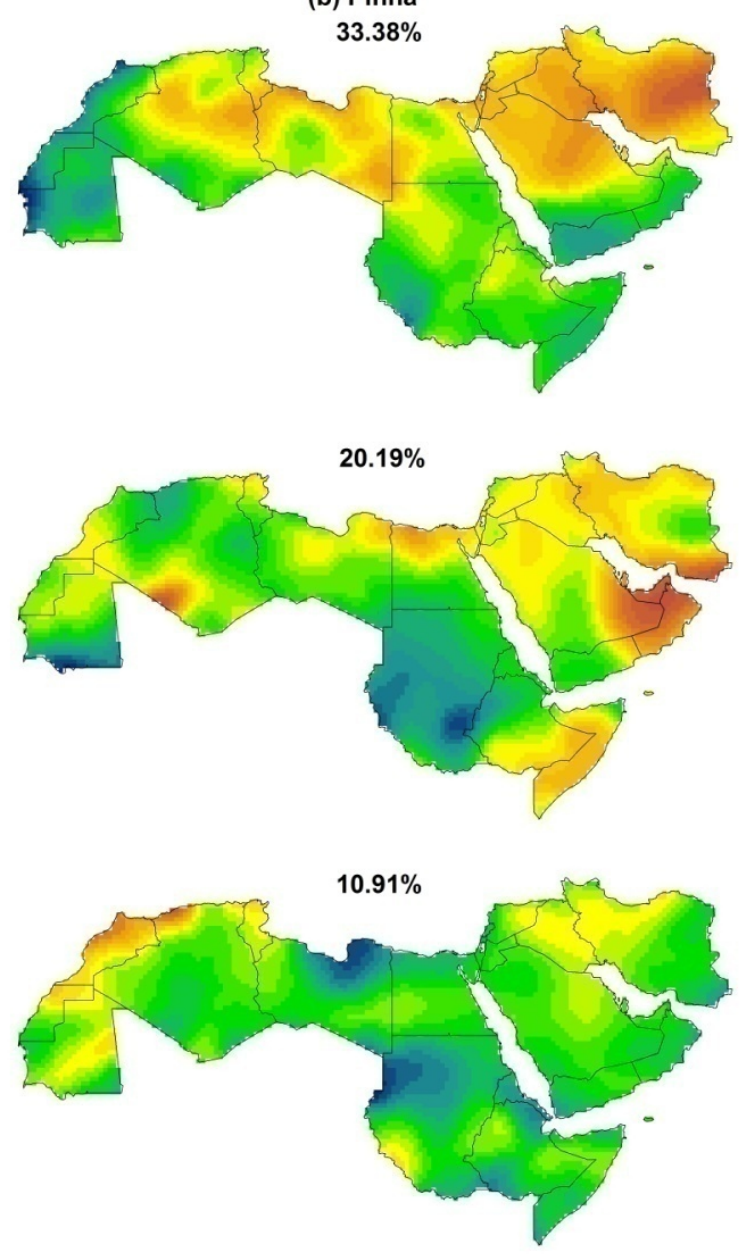

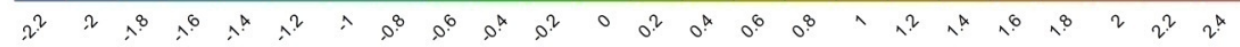

974 Fig. 11: Spatial distribution of the scores corresponding to the first three principal components of 975 each aridity index. Percentages refer to the amount of variance explained by each component, as 976 revealed by the PCA analysis. 